\title{
Joan Roís de Corella, La istòria de Leàndery Hero: edizione critica con studio introduttivo
}

\author{
Annamaria Annicchiarico
}

Università degli Studi Roma Tre

annamaria.annicchiarico@uniromaz.it

https://orcid.org/OOOO-0002-7II3-59IX

Received 22/o6/20I8; accepted 03/o8/2018

DOI: https://doi.org/I0.7203/MCLM.5.12657

Joan Roís de Corella, La istòria de Leànder y Hero: a critical edition with an introductory study

Abstract

This contribution is a further partial anticipation of the critical edition of the mythological faules by Joan Roís de Corella (I5th century) for Editorial Barcino, following a previous one also appeared in Magnificat CLM (3, 20I6). It focuses on one of Corella's most mature and significant faules, as well as one of the most prestigious testimonies both of the presence

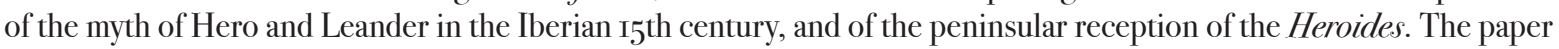
has two parts. The first part, Introduction, summarizes the current situation of the studies related to the Istòria. Next, an analysis of the literary memory that supports the faula's discursive construction is provided, aiming to demonstrate how it actualizes a game of mirroring, projections, refractions, intertextual references, and symbolic-allusive evocations that make res and characters the revival of a plurality of classical and medieval models. Such a revival becomes loaded of a new pathetic energy. Our analysis is based on certain thematic words and specific topical-rhetorical matrixes, reused either a lo profano or a lo divino, always within the idea of "dying together" and of love beyond death. It focuses on the communication strategies through which this ficció sentimentals text (a point of convergence for thematic, metaphorical and figural weaving, anchored to the Tristanian, lyrical-amorous, ausiasmarquiana, cancioneril and Passionist imagery of planctus virginis) transforms memory and reuses it into an invention. The second part of the paper is the critical edition of the text. Anticipated by the Criteria of Edition, it contains the Text, with footnotes concerning the constitutio textus, and the Critical Apparatus.

KeYwords

Medieval Catalan literature; Joan Roís de Corella; mythological narratives; Leander and Hero; critical edition; medieval Ovid.

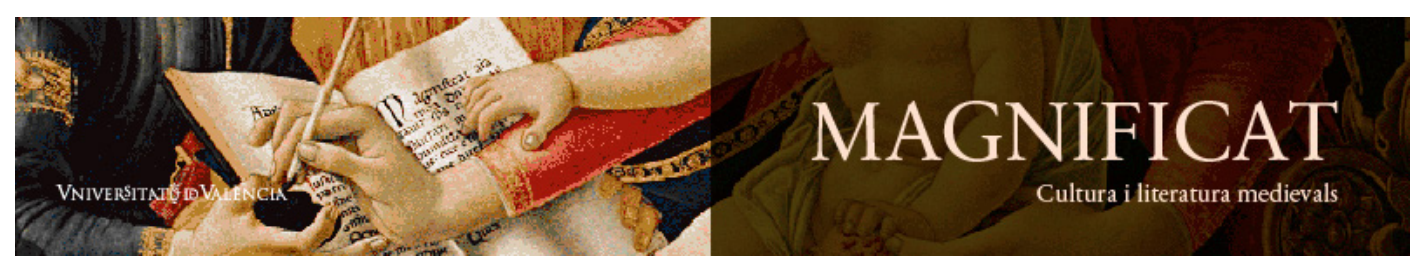

Magnificat Cultura i Literatura Medievals 5, 20I8, I53-2ОI. http://ojs.uv.es/index.php/MCLM

ISSN 2386-8295 
RIASSUNTO

Il contributo è un’ulteriore anticipazione parziale dell'edizione critica delle favole mitologiche di Joan Roís de Corella (XV sec.) per l'Editorial Barcino, dopo quella apparsa su Magnificat CLM(3, 20I6). Esso mette a fuoco una delle favole più mature e significative dell'autore, nonché una delle testimonianze più prestigiose sia della presenza del mito di Ero e Leandro nel ‘ 400 iberico, sia della ricezione peninsulare delle Heroides. Consta di due parti. La prima (Introduzione), fatto il punto sulla situazione attuale degli studi relativi alla Istòria, si addentra nell'analisi della memoria letteraria che ne sostiene la costruzione discorsiva, con l'intento di dimostrare come essa attualizzi un gioco di rispecchiamenti, proiezioni, rifrazioni, richiami intertestuali, rimandi simbolico-allusivi che fanno delle res e dei personaggi la reviviscenza, caricata di una nuova energia patetica, di una pluralità di modelli classici e medievali. Puntando su determinate parole tematiche e su specifiche matrici topico-retoriche, riusate ora a lo profano ora a lo divino e sempre in funzione dell'idea portante del "morire insieme" e dell'amore oltre la morte, si mettono a fuoco le strategie comunicative attraverso cui il testo - una ficció sentimental, fattosi punto di convergenza di intrecci tematici, metaforici e figurali ancorati nel contempo alla imagery tristaniana, lirico- amorosa, ausiasmarquiana, cancioneril, nonché a quella passionista dei planctus virginis - trasforma la memoria e il riuso in invenzione. La seconda parte contiene l'edizione critica del testo. Anticipata dai Criteri di Edizione, essa ospita il Testo, con note a piè di pagina inerenti alla constitutio textus, e l'Apparato Critico.

PAROLE CHIAVE

Letteratura catalana medievale; Joan Roís de Corella; favole mitologiche; Ero e Leandro; edizione critica; Ovidio nel Medioevo.

Annamaria Annicchiarico. 20I8. 'Joan Roís de Corella, La istòria de Leànder y Hero: edizione critica con studio introduttivo', Magnificat Cultura i Literatura Medievals, 5: I53-20I.

INDICE

o Dati - I55

I Introduzione - I57

2 Testo -174

3 Apparato - I89

4 Ringraziamenti - 193

5 Opere citate - I94 


\section{əै⿻丷木}

\section{o Dati}

Il tràdito: La Istòria de Leànder y Hero è trasmessa dal Cançoner de Maians (Biblioteca Universitària de València, ms. 728, ff. $25^{\mathrm{V}-3}$ 4r, della fine del sec. XV) ${ }^{\mathrm{r}} \mathrm{e}$, col titolo di Istoria de Leander hi de Hero feta per mestra Corela, dal Jardinet de orats (Biblioteca Universitària de Barcelona, ms.I5I, ff.I29r-I38v (I3Ir-I4Ov) la cui stesura fu ultimata il I486. ${ }^{2}$

Le edizioni: Miquel i Planas (เ9I3: 95-ІІІ9); Almiñana Vallés (เ984-I985) con la riproduzione in fac-simile del testo del ms. Maians nel I vol.; Martos (200Ia: I5I-73; 20I6: I9-94). Il testo allestito da Miquel i Planas è riprodotto con ammodernamento ortografico e modificazioni interpuntive in Carbonell (I973: I67-82), Gustà (I980:I2I-37), e in Martínez (I994: 97-II8). Riproduce fondamentalmente il testo delle edd. di Miquel i Planas e di Martos l'edizione a cura di Escartí (2OI4: II3-27). Altre: Bulbena (I896-I897: 29-46), Bulbena (I9O7: 25I-53); quest'ultima contiene solo la sequenza finale: Lo plant he mort dolorosa de Ero sobre lo cors de Leànder con l'integrazione dal ms. Maians del frammento finale - dall'epitaffio alla fine - omesso dal Jardinet de orats. Altre edizioni di carattere divulgativo: Ahuir López (I997); Lozano-Añon (1998). Per una nuova edizione dell'opera mitologica corelliana, vid. Annicchiarico (2004).

Gli studi: La Istòria, considerata già da Riquer (I964: III, 3IO) una fra le più "reeixides" delle favole mitologiche corelliane, annoverata da Carbonell fra i testi nei quali l'autore "assoleix el punt màxim de la seva qualitat com a narrador" (I973: 29), ha ricevuto attenzioni specifiche da parte degli studiosi non prima dello scorcio del '9oo. Nel quadro della riconsiderazione dell'orizzonte intellettuale di Corella e, specificamente, della rivalutazione del Corella narratore, iniziata nella seconda metà del secolo scorso, la nuova prospettiva d'indagine che si voleva aprire sul valenziano trovava, infatti, proprio nelle prose mitologiche un terreno ideale su cui confrontarsi (Badia I988: I45-I80); a partire, va da sé, da quelle che, tra le ficciones, venivano individuate come le più, a vario titolo, rappresentative e/o viste come tappe salienti di un percorso creativo: che, nello specifico dei rifacimenti mitologici di Corella consiste, appunto, come è unanimemente condiviso, in una rielaborazione sempre più autonoma e complessa delle fonti e dei modelli (Wittlin I997; Martos 200Ia: 35-36; Martos 200ib: 298).

Infatti, due aspetti della Istòria, in particolare, sono stati privilegiati dallo sguardo degli studiosi: la sua collocazione cronologica nella successione delle nove faules mitologiche pervenute, e, contestualmente, l'individuazione dei modelli di riferimento e le modalità di riuso degli stessi. Per quanto riguarda il primo aspetto, è nozione consolidata e condivisa, nonché ribadita anche di recente, che sia da collocare intorno al I468-69 - periodo in cui verosimilmente Corella ha assunto il titolo di mestre en sacra teologia (Guia i Marín I999: 46; Chiner Gimeno 20I3; 2OI4: I62; Soler, 2OI4: 209) - il punto di svolta della sua attività da una prima fase radicata nella cultura post-cortese, e centrata sulle tematiche/problematiche dell'eros, a una fase successiva dominata da interessi agiografico-scritturali. Al contempo è stata datata, specificamente, agli anni I46o-65 (Wittlin I993: 342), o intorno al I458 o poco dopo (e comunque prima del I460: Cingolani I997: 70; I998: $5^{6-58)}$, la redazione dell'intera opera mitologica. Evidentemente, in considerazione della ben nota

I. Per la descrizione e analisi codicologica del Cançoner de Maians (che contiene quasi esclusivamente testi corelliani), vid. i contributi di Martos (І999; 200іс; 2005a).

2. Per la descrizione e analisi codicologica del Jardinet de orats, vid. Torró (I992). 
connexió corelliana del Tirant lo Blanc, la cui stesura, come dichiarato dallo stesso Martorell, ebbe inizio il 2 gennaio I460 (per terminare, si ritiene, nel I464: Hauf 20II: 2IO ss.; Pujol 2OI5: IO8). Entro questi termini, gli studi su Corella, dividendo le faules in due sottogruppi caratterizzati da un diverso livello di rielaborazione delle tematiche ovidiane, inscrivono la Istòria nel novero di quelle connotate da un "ampli grau de reelaboració d'aquestes" (nella fattispecie le Eroidi: Martos 2oorb: 298; Martínez 2OII: 440; Gómez 2OI5: 226). Per quanto riguarda il secondo aspetto, ovverosia la ricostruzione della tradizione cui la lettura-riscrittura corelliana del mito si ancora, si deve a Martos (200Ib) una prima circostanziata indagine tesa ad analizzare tanto le componenti tematiche caratterizzanti il testo corelliano rispetto alle antecedenti versioni del mito, quanto le innovazioni, "attualizzazioni", e amplificationes che ne marcano l'autonomia rispetto al dettato dalle epistole ovidiane (Her., XVIII e XIX). Queste ultime annoverate da sempre come le maggiori "fonti di ispirazione", se non come l'ipotesto della Istòria (Miquel i Planas I9I3: lvi-lvii; Riquer I964: III: 3IO; Badia I988: I7 I ss.). Il contributo citato risale, quindi, lungo la trafila attraverso cui è passata l'interpretazione allegorico-morale del mito, eleggendo come punto di osservazione privilegiato due nuclei tematici di esso visti come centrali e fondanti: la navigazione notturna di Leandro e la lampada di Ero (244 ss.). Mettendo a fuoco soprattutto il Mitografo Vaticano III, l'Ovide moralisé e l'Ovide moralisé en prose, Martos evidenzia come il riuso corelliano e "la lectura moral que se’n deriva s'allunya de les exposicions al·legoricomorals que la tradició medieval li submistrava, la qual cosa no significa que no la faça servir" (250).

Gli studi successivi si sono addentrati ulteriormente nel meccanismo degli scarti e delle innovazioni del testo corelliano rispetto alle precedenti esperienze di fruizione del mitologema, classiche, tardo-antiche e medievali, dedicando speciale attenzione al modello ovidiano rappresentato dalle Metamorfosi e delle Eroidi, con i relativi accessus e glosse, e al dettato boccacciano (Martos 2000; 2005b; Pujol 2OI3; Annicchiarico 2OI4). In sostanza, penetrando nei meccanismi corelliani di riuso della tradizione, gli studi degli ultimi lustri hanno dimostrato come, su una fitta rete di richiami intertestuali e interdiscorsivi, l'autore abbia dato un impianto novellistico alla versione del mito, facendone poi uno dei testimoni catalani più significativi della ficció sentimental del XV sec.

La Istòria figura tra i testi corelliani assunti come emblematici da Martínez (20OI) per una lettura di Corella filtrata attraverso Ausiàs March (I62 ss.; vid. anche la segnalazione di un paio di parallelismi tematici a p. 192). Così come va segnalata l'attenzione prestata alla Istòria nelle note di commento al canto XLVI (Veles events) di Gómez-Pujol (2008: I85 ss.).

Nel quadro delle relazioni tra il sacro e il profano nell'opera di Corella, Garcia Sempere (I999a; 2002: I47-I53) ha focalizzato temi e motivi comuni tra la Istòria (segnatamente l'ultima sequenza di essa: Lo plant e mort dolorosa de Hero sobre lo cos de Leànder) e la corelliana Oració a la sacratíssima Verge Maria tenint son Fill Déu. Jesús en la falda devallat de la creu. Il contributo si richiama alla tradizione catalana dei planctus Mariae (Izquierdo 1994) - assumendo come punti di riferimento in particolare la Istòria de la Passió di Bernat Fenollar-Pero Martines e la Vita Christi di Isabel de Villena - e, alla luce di questa, analizza entrambi i due testi corelliani insieme a specimina testuali tratti da Lo quart. Riferimenti alla Istòria sono sparsi anche negli studi di López Quiles centrati sui fondamenti teologici e biblico-sapienziali del corpus corelliano (2007: tra gli altri, vid. quelli alle pp. 67, 68, 76, I97; e 20I4: 4I3-I4).

La fitta trama delle relazioni intertestuali tra la Istòria e il Tirant lo Blanc è stata studiata nel quadro, e nella lunga storia, della cosiddetta "connexió" tra Corella e il romanzo. Se ne sono occupati: Riquer (I949: I8-20; I990: 298-30I); Badia (I988: I72-I73); Chiner Gimeno (I99I: IO2); Garriga (I99I: 2O-22); Guia i Marín (I996: passim); Renedo (I995-I996: 339); Annicchiarico (I998: 30; 1999: 59); Pujol (I995-96: passim; 2002: I97-200); nonché Hauf (ed. 2005), la cui edizione 
registra puntualmente nelle note a piè del testo, e commenta se del caso, i prelievi intertestuali dalla Istòria.

Il contributo di Martines (2OI3), ribadendo la forte valenza figurativa del testo corelliano, propone una messa confronto della Istòria con le rappresentazioni "en figura", coeve e dei secoli XVI-XVII, del mito.

\section{Introduzione}

Sono entrambi perfetti, dotati di nobiltà d'animo, di celebrate virtù e di alto rango. S’incontrano ad una festa solenne; sono colpiti da Amore all'istante; si innamorano all'istante; cadono in una immoderata cogitatio all'istante. Vivono una storia d'amore insidiata da un destino avverso; peccano di "dismisura", e pagano con la morte l'oltranza della loro pulsione erotica: lui annegato, lei suicida col pugnale di lui, sul corpo di lui; abbracciati dalla e nella morte; all'insegna del "morire insieme" e dell' "amare oltre la morte".

Sono come tante altre celebri e infelici coppie di amanti; eppure la Hero corelliana e il Leànder corelliano, benché protagonisti di una Istòria i cui temi, motivi e immagini sono rintracciabili (e oggi quasi integralmente rintracciati) nella trafila delle riscritture classiche e medievali del nucleo primigenio del mito, sono del tutto singolari; e lo sono per essere diventati grazie alla penna del valenziano i protagonisti, inediti, di quella che oggi chiamiamo ficció sentimental, con tanto di intreccio e tanto di personaggi in linea con le prospettive di una moda letteraria corrente all'epoca; quella appunto della cosiddetta ficció sentimental. ${ }^{3}$

Lo si vede immediatamente: due innamorati di alto lignaggio, un padre dispotico, un pretendente-rivale spregevole, una nutrice confidente e complice, una attrazione morbosa, un legame proibito, un rapporto eslege, lo scacco fatale della fortuna, un finale tragico-patetico. ${ }^{4} \mathrm{E}$, a monte, una (la) moralisatio di rigore, tutta centrata sulla polarità, data a priori, tra "amor diví / amor honest" e "amor deshonest" e sul "... concepte cèntric de la honestat i de la honra de la dama" (Torró 1987: 5I); col conseguente inevitabile "rebuig de la passió”" (Pellisa Prades 20I3: 35)

È infatti unanime l'avviso che Corella, rielaborando in forma narrativa il materiale tematico delle Heroides, XVIII (da Leandro a Ero) e XIX (da Ero a Leandro), e introducendo particolari tratti da altri modelli, soprattutto italiani, abbia prodotto una "novella sentimental de llarg alè i de final tràgic que desenrotlla ... una narració completa, complexa, travada i perfectament motivada en tots els seus elements, amb una justa alternança de narració, comentaris del narrador i veu dels personatges" (Pujol 20I3: I55). ${ }^{5}$ Così come è unanimemente condiviso che abbia prodotto, nel

3. Si deve a Pellisa Prades (20I3) un'accurata analisi della ficció sentimental catalana nel quadro della ficción sentimental castigliana, nonché ultrapirenaica. Nel "genere", più propriamente definibile, secondo l'autrice, come una "moda literària" (dunque come una realtà "supragenèrica": 2I), destinata soprattutto alla lettura "en entorns cortesans (Rodríguez Risquete 2OII) i en tertúlies literàries ...” (34), il ruolo di Corella si precisa come quello “[de] l'autor que aporta més textos al corpus, $i$, de fet, la seua obra representa la consolidació del model de la ficció sentimental a mitjan segle" $(50)$.

4. L'orizzonte d'attesa della ficció sentimental è sinteticamente ben delineato da Badia (20I5: I92): “Els escriptors i el seu públic estaven familiarizats amb l’amor hereos..., amb els malentesos fatals de percepció que genera la passió, amb la pèrdua del control racional del subjecte moral afectat per l'amor, amb la caiguda en la desviació irreparable de la conducta, i amb l'aferrament morbós i tràgic al desig pertorbador".

5. Come osserva Pujol (2013: I55-I58), le uniche rielaborazioni medievali importanti del mito antecedenti la Istòria di Corella sono quella di Baudri de Bourgueil (sec. XII) inclusa nel carme I54 (Tilliette ed. I998-2002, 2, vv. II39-242), e la Leandreride di G.G. Nadal (“completata intorno al ı38I-82”: Lippi ed. r996: VII), nonché la narrazione con commento 
contempo, quella che sarebbe diventata una delle testimonianze più prestigiose della presenza del mito di Ero e Leandro nel Quattrocento iberico, ${ }^{6}$ nonché uno dei prodotti più significativi all'interno della ricezione peninsulare delle Heroides. ${ }^{7}$

In effetti, quando giunge a Corella, la storia è da tempo ben sedimentata nell'immaginario del pubblico medievale con i suoi temi e motivi dominanti, nonché con le sue immagini più di effetto; e ben sedimentata è anche la lezione morale che la tradizione esegetica ne aveva tratto: una storia d'amore e morte proponibile come esempio della irrazionalità della passione, e, dunque, spendibile vuoi a fustigazione dell'amore/cupiditas vuoi a elogio della castità e/o dell'amore coniugale. ${ }^{8}$ Infatti, travolti dalla passione e schiacciati del giogo capriccioso-punitivo della fortuna, nonché vittime di convenienze morali e sociali, i due giovani si sono istituiti da gran tempo a figure esemplari dell'amore-passione e del perpetuarsi dell'amore oltre la morte. Ma, nel frattempo, è come se fossero andati aldilà del loro ruolo, configurandosi come simbolo di un simbolo: quello della navigazione fortunosa, se non fatale, quale metafora per eccellenza del travaglio amoroso.

Tant'è che, se a fornire a Corella la tela di fondo del racconto sono le due summenzionate epistole ovidiane, la sua Istòria è, alla fine, una riscrittura in proprio, nella quale una pluralità di antecedenti classici e medievali si compatta alla tradizione trobadorica rivissuta attraverso il filtro di voci liriche altre, in specie quella ausiasmarquiana, centrate sui temi dell'assenza, dell'ossessione, del martirio, del naufragare dell'io, dell'amore oltre la morte: "Els més determinants són els amors clandestins de Píram i Tisbe, la Fiammetta de Boccaccio i l'amor matrimonial de Cèix i Alcíone (Metamorfosis, XI, vv. 4IO-748), que també susciten la memòria de dos poemes ausiasmarquians d'inspiració anàloga: la cançó Veles e vents (XLVI) i el més sublim dels cants de mort (XCII, vv. 245-50)" (Gómez 20I5: $\left.23^{\mathrm{I}-} 3^{2}\right)$.

allegorico-morale dell'Ovide moralisé (primo trentennio del XIV sec.) (IV, 78-9O, vv. 3550-373I).

6. Sulla storia del mito in Spagna, vid. Moya del Baño (ig66). Sulla presenza e sul ruolo del mito nella storia della metafora della navigazione procellosa come figura delle vicissitudini della vita e dell'amore, nel contesto iberico, dagli antecedenti medievali all'età barocca, vid. la documentata indagine di Sarmati (2009). In un quadro più ampio, sulla suddetta metafora - dal mondo classico-cristiano, alla letteratura cortese, alla poesia cancioneril del Quattrocento spagnolo -, resta fondamentale l'excursus di Pulega (r989). Importanti testimonianze, a riguardo, sono il decir allegorico di Juan de Dueñas, La nao de amor (Presotto ed. 1997) e le coplas della Nao de Amor del Comendador Escrivá (Ravasini ed. 2008: 71-77, 154-58). Infine, una articolata ricostruzione della ricezione della favola dal mondo antico al Rinascimento, condotta dalla prospettiva della "moralización", è in Morros Mestres (20I3).

7. I momenti salienti della ricezione e riuso delle Heroides nel contesto iberico sono rappresentati dalle compilazioni storiche alfonsine (Brancaforte ed. 1990), dalla traduzione catalana di Guillem Nicolau, terminata il I390, e dal Bursario di Juan Rodríguez del Padrón (Saquero Suárez-Somonte - González Rolán 1984, 20IO). Quest’ultimo è basato su una traduzione castigliana quattrocentesca anonima, trasmessa dal ms. 5-5-16 della Biblioteca Colombina di Sevilla, la quale, a sua volta, è una "versión literal" (Pujol 20I4: 455) di quella catalana. In merito ai rapporti interni fra queste traduzioni e alla centralità del ruolo di quella catalana, vid. Pujol (20I4: 455-56): “Como se ha mostrado en Pujol 2005 ... el anónimo traductor vertió íntegra y literalmente la versión catalana de las Heroidas ejecutada por el clérigo y funcionario de la cancillería real catalano-aragonesa Guillem Nicolau entre I389 y 1390 ... El manuscrito de la versión castellana conserva, además, un completo aparato de glosas marginales de las que hablan los documentos relativos a la traducción catalana, pero que no han conservado los testimonios manuscritos de esa primera versión (aunque sí ofrecen indicios de su existencia) ... Las introducciones o accessus particulares a cada epístola del texto catalán y de su traducción castellana, así como las glosas marginales de esta última, nos permiten remontarnos hasta manuscritos latinos escolares que incorporaron las introducciones y glosas del comentario a Ovidio de Guillermo de Orléans (los Bursarï ovidianorum, de ca. I200) muy parecidos al manuscrito que debió servir de modelo a Guillem Nicolau".

8. Ne è una prova il passo di chiusura de Lo johí de Paris, testo programmatico in cui Corella offre un saggio d'interpretazione allegorico-edificante di una fabula classica, il giudizio di Paride, e ne individua il sen nell'immane, esemplare, catastrofe generata dalla lussuria. Il testo si chiude, infatti, con la citazione di Leandro e Ero eletti quali vittime emblematiche della fol'amor (Annicchiarico 20I4: 295). Per Ero e Leandro come proverbiali esponenti dell'amour fou, vid. Barbieri (20II: 242, n. 26) e Lechat (2002). 
D’altronde, che Ero e Leandro fossero i protagonisti di una storia, oltre che bella, particolarmente struggente, e con immagini di particolare impatto emotivo, quali l'alta torre di Ero, la lanterna-faro nella notte, la complicità della luna e dei pesci, i flutti tempestosi, il naufragio della nave-nocchiero-passeggero, la morte di lui, l’urlo, lo schianto, e il suicidio di lei, è Fiammetta ad attestarlo. Quando, da grande consumatrice e interprete di classici, passa in rassegna casi estremi di dolori estremi, mai estremi in ogni caso quanto il suo, e dichiara, di fronte allo strazio di Ero, di provare per lei "molta più [compassione] che [per] nessuna delle donne ancora dette". Tanto da ritrovarsi a piangere, proprio lei Fiammetta, non più per le proprie disgrazie, ma, per Ero (Annicchiarico 2OI4: 29I). Per Ero, e non per altri; benché abbia ammesso, un attimo prima, che il dolore nel quale maggiormente identifica il proprio sia quello della relicta per eccellenza, Didone: "Viemmi poi dinanzi con molta più forza che alcuno altro il dolore della abandonata Dido, però che più al mio simigliante il conosco quasi che altro alcuno." (Delcorno ed. 1994: VIII, 5 , I). ${ }^{9}$ Didone che, non a caso, decide di finire anche lei "col ferro" dell'amato.

Dunque, una storia straordinariamente patetica che certo non poteva non apparire a Corella, il quale con Fiammetta condivide appieno la vocazione all'empatia compassionevole e la voglia di commuovere, un exemplum perfetto, sia per il succo morale che ne avrebbe tratto, sia per le potenzialità iconiche della metafora nautico-amorosa. Un "caso pietoso" della mitografia erotica classica, rimodellato novellisticamente e riconfigurato all'insegna del patetico e del sentimentalismo drammatico a oltranza; alla "gravitas" del contenuto (e della correlata lezione morale) il sistema ideologico-estetico di Corella non avrebbe esitato a garantire il decorum dovuto: con opportune scelte retoriche e stilistiche, con registri alti e toni lacrimevoli, con una tramatura ritmico-sintattica funzionale all'esigenza di enfasi oratoria, con la ricorrenza nell'organizzazione sintattica di forme cadenzate, con un discorso prosastico percorso da moti di liricità, con inserti lirici chiamati a esprimere momenti culminanti della tensione emotiva.

Sappiamo che la pièce è considerata una delle prove più valide del secondo tempo della fase mitografica, in simmetria con le Lamentacions che, a parere degli studiosi, figurano tra i prodotti più maturi del primo tempo (Carbonell I973: 29; Martos 2OoIa: 33, 35-36; Martos 20OIb: 296; Gómez 2OI5: 226, 23I). Nel contempo, sappiamo che la Istòria è legata da un filo ideale alla Lamentació di Tisbe, l'ultima delle tre che costituiscono le Lamentacions (o Lojardí de amor), per via del tema dell'amore, in principio onesto e legittimo, ma ostacolato dalla società e perseguitato dalla fortuna avversa, nonché per il tema dell'amore oltre la morte: il "morire insieme", lei nelle fredde braccia di lui - entre sos frets braços / entre.ls braços frets -, invocando un sepolcro comune.

Così risuona, infatti, da un trist verger dell'oltremondo, la voce della Tisbe corelliana:

“... ‘... E als déus més soplich, puix en vida a nostres desigs tant han contrastat, ara, aprés mort, ordenen que.ls nostres cossos en un mateix sepulcre reposen’.

Encara dient tals paraules, me lançí damunt aquella espasa que del cos de Píramus sangonosa exia, leixant ma vida entre sos frets braços. Han-me portat los fats en aquest trist verger, en lo qual sempre les desiguals penes de amor nos tribulen”. (Annicchiarico ed. 20I6: 25, 11. 534-39)

e così si chiude la storia della Hero corelliana:

Encara dient aquestes paraules, de greus plors acompanyades, tirà de la bayna la copagorja que la correja de Leànder mort sostenia, e, més lo pom sobre lo cor de Leànder e sobre lo seu la punta, lançant lo cos ab esforç de amor cruel pesada sobre.l de Leànder, espirà la miserable Hero, entre.ls

9. Qui, e in seguito, s'intenda effettuato il confronto con la traduzione catalana della Fiammetta (Annicchiarico ed. I983-87). 
braços frets de aquell mort per qui moria. (1l. 489-93)

Una Hero che poco prima abbraccia il corpo di Leànder e gli inonda di lacrime il viso gelido:

Hi, estesa sobre lo cos, besant la boca freda, mesclava les sues làgremes calentes ab l'aygua de la mar amargua. E volent pronunçiar, no podia ni sabia tristes paraules a tanta dolor conformes; hi ab les mans tremolant los ulls de Leànder obria, los quals primer ab la boca hi aprés ab los ulls besant axí de abundants làgremes omplia, que semblava Leànder, encara mort, plorant la dolor de la sua Hero viva, planyent deplorava. (1l. 426-32),

richiamandosi certamente alla Tisbe ovidiana:

et laniata comas amplexaque corpus amatum uulnera suppleuit lacrimis fletumque cruori miscuit et gelidis in uultibus oscula figens (Barchiesi ed. 2OII: Met., IV, vv. I39-4I)

... o multum miseri meus illiusque parentes, ut quos certus amor, quos hora nouissima iunxit, componi tumulo non inuideatis eodem.

(ibid., vv. 155-57)

... dixit et aptato pectus mucrone sub imum incubuit ferro, quod adhuc a caede tepebat. (ibid., vv.I62-63),

ma richiamandosi anche, nel gesto tristaniano del tenere l'amato "entre ses bras" e di baciargli la bocca e il viso, ${ }^{\mathrm{IO}}$ nonché nell'invocare un sepolcro comune, ${ }^{\mathrm{II}}$ ad altre ben note eroine. Ne seleziono solo alcune, scegliendole tra quelle che ai baci sul viso aggiungono quelli degli/sugli occhi dell'amato. E lo faccio per il rilievo che assume nella Istòria corelliana, come vedremo, questo "dettaglio". ${ }^{22}$ Ecco, innanzitutto, la Tisbe protagonista del poemetto oitanico (XII sec.):

Que nos contiegne uns seulz tombleaux,

Andui nos reçoive uns vaisseaux.

(Branciforti ed.I959: vv. 899-900)

Parmi le piz, souz la mamele,

S'en referist la damoisele.

(ibid., vv. 92I-22)

Le cors acole et si l'embrace,

Baise les iex, baise la face,

Io. Per "entre ses bras" come sintagma esemplare, "cifra della sintesi dell’unione degli amanti oltre la morte”, vid. Punzi (2007, in part. I6-I9).

II. Per il tema della sepoltura comune degli amanti in testi emblematici del medioevo gallo e italoromanzo, vid. Mezzetti Radaelli (2007) e, con ulteriori puntualizzazioni, Delcorno Branca (2OI2, in part. 338-39). Per una ricognizione sul medesimo tema, nella prospettiva del "valore figurativo e narrativo" dell'immagine sepolcrale, anche in ambito castigliano, vid. Murgia (2015).

I2. Non mi riferisco, naturalmente, al gesto come forma corrente di effusione tra amanti: per questa, valga, per tutte, una testimonianza dal Tirant lo Blanc: "E Tirant no curà de les paraules de la princessa, sinó que s'acostà envers ella e pres-la en los braços e besà-la moltes vegades los pits, los ulls e la boca." (Hauf ed. 2005: CLXXXVIIII, 788). 
Baise la bouche par grant cure,

Tant com sens et vie li dure.

(ibid., vv. 925-28)

Quindi la Danae del lai di Narciso che stringe a sé l'amato, appena morto:

Ele le baise, ele le tient,

Ele se pasme, puis revient,

Ele l'acole, ele l'enbrace,

Baise les eus, baise la face.

(Thiry-Stassin-Tyssens ed. 1976: vv. 979-82)

E così ancora, la protagonista del lai dei Deus Amanz:

Or vus dirai de la meschine.

Puis que sun ami ot perdu,

Unkes si dolente ne fu.

Lez lui se cuchë e estent,

Entre ses braz l'estreint e prent;

Suvent li baisë oilz e buche.

Li dols de lui al quor la tuche:

Ilec murut la dameisele,

Ki tant ert pruz e sage e bele.

(Rychner ed. 1966: vv. 230-38)

D'altronde, è un fatto che i baci sugli occhi siano un motivo ampiamente frequentato anche dalla diffusissima, secolare, tradizione dei planctus della Vergine. Lo dimostra, a titolo di esempio, il Liber de passione Christi et doloribus et planctibus matris eius (di autore oggi identificato in Oglerio di Lucedio):

Stabat ad caput exstincti filii sui mater Maria lacrymis faciem ejus rigans; per diversa torquebatur suspiria interius, frontem, et genas, oculos, quasi simul et nasum, omniaque frequentius osculabatur ... Rigabat lacrymis exstinctum filii corpus expositum ... $(P L, \mathrm{I} 82, \mathrm{cl} . \text { II } 39 \mathrm{~A})^{\mathrm{r} 3}$

Ed è un fatto che il motivo sia ben corrente in testimoni della letteratura passionista coeva di Corella: valga come testimonianza la Istòria de la Passió di Bernat Fenollar e Pere Martines:

Tenia la verge lo cos, estant seyta,

besant lo seu fill ab pena molt gran.

Besant-li la boca, los ulls y les galtes,

les mans....

(Garcia Sempere ed. 2002: st. 385, vv. 4146-52),

e la Vita Christi di Isabel de Villena:

E, venint la dolorosa mare als ulls, posà la boca sobre aquells e estigué gran peça sens parlar, llavantlos abundosament d'amargoses llàgrimes; e dreçant-se dix: "Caligaverunt in morte oculi tui, et illa

I3. Il passo è all'attenzione anche di Garcia Sempere (ı999a: ı72). 
magna luminaria, que illuminant orbem, ad horam extincta sunt." (Escartí ed. 20II: CCXIX, 450)

Considerazioni analoghe suscitano gli altri punti-chiave del passo, quello finale, al quale mi sono richiamata in apertura; a dire, il vagheggiamento del sepolcro comune e il desiderio di un epitaffio ad hoc. Infatti, nel momento stesso in cui queste idee-forza suggellano la relazione di continuità tra la Lamentació di Tisbe e la Istòria di Hero, le stesse idee valgono a evocare, nel contempo, una rete densa di parallelismi tematici che, tra il profano e il sacro, fanno risuonare nella voce di Hero ancora altre voci, altri universi culturali. A dire, ora la passionalità epico-tragica, o elegiaca, delle eroine del passato; ora la fol'amor tristaniana; ora il cupo misticismo erotico della novela sentimental; ora la com-passione della mater dolorosa dei planctus Mariae. In quest'ultima compreso, e con grande rilevanza di rimandi simbolici e allusivi, il planctus contenuto nella celebratissima Oració a la sacratíssima Verge Maria dello stesso Corella. ${ }^{\mathrm{I}}$

Tornerò via via sull'argomento, perché mi preme, dovendo dare spazio ad osservazioni a questo punto necessarie, fare un passo indietro. Ovvero riprendere la Lamentació di Tisbe, considerata l'indubbia affinità di situazioni, vicissitudini e personaggi che fanno di essa un universo mentale ed espressivo parallelo a quello della Istòria; un'affinità che si traduce poi, con tutta evidenza, nella analogia della funzione esemplare che i due miti assolvono nella rilettura-riscrittura corelliana.

È ben noto che nell'immaginario medievale fosse particolarmente radicato e vivido il ricordo della vicenda di Piramo e Tisbe e del loro "modo" di finire insieme, come anche di recente è stato opportunamente ricordato (Pujol 20I3: I75): "la recreació poètica de l'episodi ovidià de Píram i Tisbe (Met., IV, 55-I66) era un exercici habitual a les escoles de gramàtica del segle XII ... I no cal dir fins a quin punt la recreació retòrica dels planys de Tisbe...el seu desig de sepultura conjunta i la descripció del seu suïcidi en són moments essencials que es projecten sobre altres històries tant d'origen antic com de tradició medieval". Tant'è che, a riguardo, mi sembra significativo il passaggio del Filocolo in cui Florio, venutosi a trovare di fronte al sepolcro (falso) di Biancifiore, sembra dare come canonico, quasi fosse un protocollo, il "modus moriendi" scelto da Tisbe:

- O Biancifiore, leva su, guatami: apri gli occhi avanti ch'io muoia, e prendi di me quella consolazione che io di te avere non potei. Io ti farò fida compagnia. Io per seguirti userò l'uficio della dolente Tisbe ... Io vengo: riceva la tua anima la mia graziosamente, e quello amore che tra noi nel mortale mondo è stato, sia nell'etterno -. Questo detto, si levò di sopra la sepoltura, la quale delle sue lagrime tutta era bagnata, e tratto fuori l'aguto ferro, dicendo: - Il misero titolo della tua sepoltura, o Biancifiore, sarà accompagnato di quello del tuo Florio -, si volle ferire con esso nello angoscioso petto. (Quaglio ed. I967: III, 63, I2-I4)

D'altronde, a dimostrazione che la Istòria corelliana dei due giovani amanti ellespontiaci dialoghi sin dal primo momento con il modello di Piramo e Tisbe lo dimostra il suo stesso passaggio liminare: il prologo; il quale, nelle poche righe di presentazione dei personaggi, non lascia dubbi a riguardo. Hero brilla di ínclita fama per alt enteniment, gràcia e bellea (1l. 6-7), Leànder altrettanto per alta perfecció, seny e gentilea (1l. 8-9). L'unica differenza tra i due sta nell'essere l'uno donzella, l'altro home: esattamente come nel poemetto oitanico si dice di Piramo e Tisbe:

I4. Fondamentali a riguardo i lavori di Garcia Sempere I999a, I999b, 2000, 2002: I47-I53. Più in generale, sui planys catalani: Izquierdo (I994); Garcia Sempere-Martín Pascual (2009). Per la tradizione manoscritta e a stampa della Oració - trasmessa dal Cançoner de Maians e data alle stampe come testo di chiusura ne Lo passi en cobles (incunabulo del I493, ristampato il I5I8) e ne Lo quart del Cartoxà (stampato il I495 in due edizioni e ristampato il I5I3) -, vid. Ferrando-Escartí (I998); Martos 20I4: 49I ss. 
Li riche home orent deus enfanz

De grant biauté et d'uns samblanz,

L'un fu vallet, l'autre meschine:

Plus biaus n'orent rois, ne roine.

(Branciforti ed. 1959: vv. 5-8)

Il che non è irrilevante, se pensiamo che la specularità fra i due amanti in virtù, bellezza, condizione sociale, lambisce concetti come l'alter idem, la paritas, il pares atque aequales in amore sul cui terreno si realizza quell'unione delle due anime, o delle persone, in una sola, il sunt duo, nec duo sunt, ${ }^{15}$ al quale alludono reiteratamente, mutatis mutandis, enunciati chiave espressi in momenti chiave sia da Leànder che da Hero. Il primo: "e lo meu cos és la fusta hon l'ànima de Hero mia" (1. 224); quindi Hero: "ànima e vida mia ... ni ab tal tempestat lo teu cos, meu, a la furiosa mar acomanes" (1l. 317-I8). E ancora Hero soprattutto nel passaggio che la descrive di fronte all'ombra di Leànder (miei i corsivi):

Si est Leànder, atura ab mi fins que de Leànder lo cos arribe, hi, esperant, pren lo meu per çerta posada; descança un poch en la casa hon, per amor, ab gran delit reposar acostumes. E no pensses, ànima mia de Leànder, larch espay yo·t detingua: comporta que al teu cos, meu, yo done sepoltura, hi aprés, ensemps ab la mia, devallaràs als regnes de Plutó, perquè un carçre, una pena, unes cadenes, aprés la mort liguen aquelles dos ànimes, les quals una amor havia liguat en vida; e axí, los cossos morts, abraçats, estaran en un sepulcre, e nosaltres, en dolor vivint, juntes en una pena (ll. $397-405)$,

dove a marcare il sunt duo, nec duo sunt è l'occorrenza insistita dei possessivi e la derivatio un, una, unes.

Col brano appena citato siamo già nel cuore della seconda parte, a un passo dalla conclusione tragica. Leànder è già morto; ma Hero ignara lo attende. Nel tormento dell'attesa, Hero la fa da eroide perfetta; da "Fiammetta" perfetta. Teme la furia delle onde; invita l'amante alla prudenza; teme dell'amante pigrizia e indifferenza (1l. 3IO-II); teme possibili rivali (1l. 382-86); è colta da cupi presentimenti; ne parla con la nutrice (1l. 346-5I); "adora" la roba di Leànder (mirant contemple la roba del qui ab tan gran desig espere, 1. 352); sale con la nutrice sulla torre; prorompe contro la fortuna avversa, e, lo fa con toni alti, nobili, e non senza trascurare una farcitura "mitologica" quasi d'obbligo (O, quant fóra millor, Leànder, quant aprenguist de nadar, ab l'artefiçi de Dèdalus, 11. 329-30; Però yo.m recort que.l fill de Dédalus, indiscretament volant, 11. 336-37). ${ }^{16}$ Poi vede il corpo di Leànder, è pronta al suicidio e, dunque, all'ultimo gesto, all'ultimo atto.

L'ultimo atto, appunto. Come ho già accennato altrove (Annicchiarico 20I4: 3I2), la scena finale dell'opera, quella in cui Hero pone fine ai suoi giorni con modalità “alla Tisbe”, preparata com'è

I5. A riguardo, vid. il saggio di Gaggero (2005) sul tema della somiglianza/parità fra amici/amanti; qui, confrontando il Piramus et Tisbé col poemetto di Matteo di Vendôme dedicato al medesimo mito ("Mente pares, par forma beat, par gracia morum, / par generis titulus, par pietatis honor. / Sunt similes facies, solus dissimilis sexus / audet eos reliquis dispariare pares"), l'autore annota: "Per significare l'amore che trasforma in un solo essere Piramo e Tisbe si fa qui riferimento, da un lato, ad una unio mentis ..., dall'altra, pur nella distinzione delle persone fisiche, ad una paritas formae che si spinge fino alla rassomiglianza dei visi: solo il sesso, ci viene detto, distingue i due protagonisti” $\left(77^{-78)}\right.$.

I6. Avere le ali di Dedalo è già nelle aspirazioni di Leandro: "Nunc daret audaces utinam mihi Daedalus alas" (Fedeli ed. r999: XVIII, v. 49); come lo è di Fiammetta, sia pur in diverso contesto: "Oimè! Ora fosse a me lo 'ngegno di Dedalo o li carri di Medea" (Delcorno ed. 1994: VI, I2, I5; e 346, n. 43). 
con un crescendo di pathos dalle sequenze del secondo blocco narrativo, ${ }^{17}$ si configura quasi come una Pathosformel, o, una imago agens, o come, ancora, il riquadro centrale di un retaule intorno al quale si dispongono in comparti laterali le altre sequenze narrative.

Si configura, cioè, come il momento risolutore-rivelatore, in cui le istanze etiche ed estetiche sottese alla pateticità-compassione confluiscono in una compiuta sintesi figurativo-performativa; a dire, il momento in cui la memoria letteraria attualizza tutte le potenzialità di drammatizzazione messe in campo, stagliando parole, cose, gesti, che, nella loro intensità icastica, riflettono "schemi" contenutistico-retorici insiti nella mente. Dei quali, richiamando quanto detto da altri in altri campi d'indagine, si può dire che nel prendere forma, "si collocano alla frontiera fra parola e immagine, fra visibile e invisibile, e anche fra lettura e scrittura, fra memoria e invenzione, fra esegesi e riuso" ${ }^{8}$

Insomma, è indubbio che la sequenza finale, con Hero che piange sul corpo senza vita di Leànder, che chiede un'unica tela funeraria per entrambi i corpi, che invoca un'unica urna, che offre il proprio sangue come unguento, che stila l'epitaffio desiderato, che si trafigge col coltello che Leànder portava con sé agganciato a una correggia - unico accessorio, insieme alla camicia filata da Hero, che lo accompagna nelle traversate notturne -, sia il cuore pulsante, il fulcro, del racconto: un discorso narrativo connotato, sin dall'inizio e nel profondo delle sue fibre, dal senso della perdita, del lutto, della morte. Lo vediamo già nella scena iniziale dell'incontro tra i due giovani avvenuto in occasione di una festa solenne: Leànder volge lo sguardo, innamorandosene immediatamente, a Hero, e lo fa "ab modesta y entristida continença dreçà la vista, que axí u disponia la iniqua Fortuna" (11. I4-I5).

Lo vediamo, in misura crescente, nei cinque inserti in versi - per tre volte messi sulle labbra di Leànder, per due su quelle di Hero - che sgorgano con tutta naturalezza da una prosa concepita, non per nulla, come "vulgar poesia". ${ }^{19}$ Così nelle parole di Leànder: "que tinch reçel la mort prest no.m asalte" (l. 67); così nel passaggio ominoso di Hero, proiettata già dalle prime battute su un più felice futuro di coppia nell'aldilà, in perfetta regola col postulato "anima verius est ubi amat quam ubi animat" che, di lì a poco, intrecciandosi alla metafora nautico-erotica, diverrà il filo conduttore della Istòria,

Del món no·m dolch, que ma vida vull perdre, perquè, del cos l'esperit ja delliure, pugua, volant, estar prop de Leànder (ll. IO5-OZ)

Lo vediamo, ancora, nei vari interventi dimostrativi e ammonitori della voce narrante, che proiettano sull'orizzonte, cristiano, della dannazione eterna il futuro degli amanti lussuriosi, facendo da mesta e amplificante cassa di risonanza all'ineludibile giudizio divino. A iniziare dal passo riportato di seguito, in cui è da notare il riferimento specifico alle responsabilità di Hero:

I7. Quello che, su un totale di i8 sequenze narrative, incluso il preambolo di pochi righi, anticipato da una sorta di sequenza-ponte (Partís Leànder de la çiutat de Cestos ab conçert e gran alegria), verte sul precipitare degli eventi: la tempesta, l’imprecazione di Leànder contro la furia delle onde, l'annegamento, l'attesa vana di Hero, lo strazio e il lamento di lei sul corpo di lui, il suicidio.

I8. Vid. Bolzoni 2OO2: 47; e, ancora, ibid., XXVIII: "Rete di immagini vuole significare sia la rete che le immagini costruiscono, legandosi fra di loro, sia la rete che ogni immagine costruisce dentro di sé e intorno a sé, una rete di ricordi e di associazioni creative".

I9. Vid. Badia (I988: I5-56): una prosa d'arte, ovvero, nobilitata al massimo delle "seves potencialitats sintàctiques ... per tal d'estar a l'altura de la magnitud de la doctrina que la «poesia» estoja” (ibid., I53); come dire una "prosa-poesia” tramata su un sorvegliatissimo vulgar col quale ottenere che, in base al principio di convenientia, all'alta nobiltà del contenuto morale non possa che corrispondere la magnificenza retorico-prosodica delle forme: l'alt e gentil estil. 
O benaventurats aquells qui, servint a Déu, per regla de virtuosa vida los seus manaments contemplen, e, qualsevol cosa los esdevingua, per no res la estimen, puix a Déu no sia ofenssa! Quant fóra millor a Hero soferir qualsevol tristor ho pena, ans que furtadament contractar de matrimoni ab Leànder! E si ans per dolor fos morta, contrastant a viçi, fóra la sua mort vida eterna, digna de premi, hi ara en los inferns no sentira aquella pena inhefable que.ls miserables desesperats eternament senten. (1l. I63-69), ${ }^{20}$

in linea col ruolo determinante attribuito dalla macchina narrativa alla componente femminile della Istòria: una eroide preda della passione e decisa nei suoi propositi ("és Leànder, al qual ... yo per marit desige", 11. 134-35), e una anus decisiva nel determinare il corso degli eventi: "prometent a la enamorada criada per marit a Leànder" (11. I56-57); "ab la discreta vella conçertant acordaren

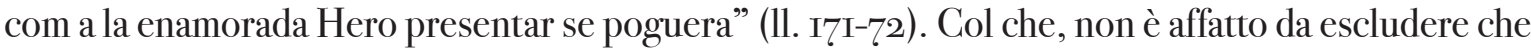
nell'apostrofe rivolta segnatamente ad Hero agisca il sovrasenso allegorico-morale che l'esegesi tardo-antica e medievale (accessus, commenti, glosse) aveva attribuito alla favola; valga per tutti, l'esempio de l'Ovide moralisé dove Ero (e Sesto) non solo è identificata con le scaturigini stesse della lussuria, ma anche resa, in una moralizzazione di segno inverso, figura Christi; e, dunque, identificata con la sapienza divina, artefice della redenzione del viator (Leandro), che, dal mare tempestoso delle passioni terrene, attinge il Paradiso. ${ }^{21}$

E va da sé che il passo della Istòria poc'anzi citato preannunci l'esclamazione-appello-condanna dell 'auctor che, quando ormai gli eventi sono a un passo dal punto di non ritorno con l'imminente ultima, fatale e folle, traversata di Leànder, distilla dall' hic et nunc della vicenda dei due giovani il suo valore esemplare:

O escura seguedat d'aquells qui desordenadement amen! E ab quin ànimo, ab quina sotliçitut $\mathrm{e}$ diligènçia treballen ensemps l'ànima e la vida perdre! $\mathrm{O}$ animosa por de aquells qui reçelant temen los perills de viciós morir e viure, e, ab invençible e discret ànimo, per lo regne del cel la vida abandonen! (11. 253-57)

Infine, ecco apparire, con l'approssimarsi del fatale ultimo agguato della tyche, i due inserti lirici ancora più tragicamente ominosi di Leànder. Il giovane preannuncia, in tutti i suoi tetri dettagli quello che accadrà dopo la sua morte, avendo cura d'inscrivere idealmente Hero (la plorosa) in una catena di non-rimanti dalla forte valenza semantica ed iconica (càlzer, sepoltura, tomba): ${ }^{22}$

ho pendré port en la ylla de Cestos, ho beuré prest de la mort lo trist càlzer. $\mathrm{Y}$ ab vostres mans donant-me sepoltura,

20. Come, d'altronde, ribadito nel menzionato (vid. n. 8) passo de Lo johí de Paris: “... Quant li fóra millor al miserable Leànder que la sua Hero, ab castedat onesta als seus desigs contrastant, de abduys hagués delliurat la vida!” (Martos ed. 200га: 3I3, ll. 498-50о).

2I. "Toute femeline luxure / Naist en sexte, membre de feme" (Boer ed. I9I5-38: IV, vv. 3597-98); "Par Hero puis prendre et gloser / Cele devine sapience" (vv. 3665-66); "Mes la devine sapiance / ... Si le trait de l'amere mer / D’enfer au saluable port / Plain de pardurable deport.” (vv. 372I-3I) . A riguardo, vid. Morros Mestres (2OI3: 227 ss.).

22. Per i versi estramps corelliani e per la scelta da parte dell'autore di rimanti funzionali al "caràcter visual de les seves construccions poètiques”, rinvio a Pujol (ı988-89: 77-79): "la concretesa dels mots-rima usats té molt a veure amb les imatges o, més precisament, amb els referents plàstics de la seva obra" (79). Più in generale, per gli estramps nella tradizione catalana, vid. Di Girolamo-Siviero (I999): "I continuatori quattrocenteschi degli estramps si servono di un rimario (di un non-rimario, dovremmo dire) ormai codificato e ripetitivo. Immancabili sono parole come sepulcre, cambra, segle, ungla, carçre e così via, a cui si mescolano non-rimanti del tutto banali, come per esempio, anche nel raffinatissimo Corella, luna, humanes, veure, vida, perfino il verbo sia e l’aggettivo possessivo mia". 
vós, per qui muyr, tanquar-m’eu dins la tomba,

lavant lo cos, de làgremes ab l'aygua.

No us espanteu besar ma boca freda (1l. $\left.247^{-52}\right)$

Cuyta, cos mort, que l'amor que $\cdot$ fa perdre

te guiarà fins al peu de la torre:

seguint del foch la miserabl-ensenya,

ffes-te present a la plorosa Hero (1l. 290-93)

Dove sono da notare il trist càlzer, appunto, e la boca freda, ambedue con alto tasso di interdiscorsività. Il primo, metafora del "bere l'amore / bere la morte", evocativo della imagery tristaniana, della tradizione amorosa tout court, e dell'eucarestia "a lo profano" risonante a sua volta dell'iperbole sacro-profana cara alla tradizione cancioneril e alla ficción sentimental. Di più, evocativo della passione di Cristo, e dunque connesso, con forte legame intertestuale, alla medesima su ricordata Oració di Corella. ${ }^{23}$

La seconda, la boca freda, di nuovo un sintagma, ${ }^{24}$ rimanda al besar fret ausiasmarquiano (XCV): l’ultimo bacio all'amata appena morta: “Quant l'espirit del cors li viu partir / e li doní lo derrer besar fret"): ${ }^{25}$ ultimo e freddo bacio che, a sua volta, fa da catalizzatore di altre associazioni tematiche ausiasmarquiane e, prima di tutto, rimanda all'idea, su cui riflettevo più su, del "duo in carne una", fulcro tematico del canto XCII. La "metafora coniugale", ${ }^{26}$ che di tale canto nutre la sostanza poetica e narrativa, sta a significare l'unione indissolubile di corpo e anima oltre i confini della vita e, dunque, s’identifica con l'idea portante della Istòria, a dire quella dell'impossibilità di vivere senza l'altro e di sopravivere all'amante scomparso. Non è un caso che esso si chiuda con la cupa immagine dell'amante che esprime il desiderio di essere collocato, poco prima di morire, accanto al cadavere dell'amata e di abbracciarlo:

23. Per un esempio di impiego del sintagma in chiave religiosa, vid. la Istòria de la Passió: "Los seus tots lo dexen, la creu sola l'empara, / donchs, sola, vós sola, girau-li la cara / primer que lo càlzer amarch de mort gust” (Garcia Sempere ed. 20O2: st. 278, vv. 3032-34).

24. Assai pertinenti, a riguardo, le riflessioni di Meneghetti (2015: 44): “... la filiera delle reminiscenze (figurative $o$ letterarie, in fondo poco importa) che fondano la costruzione discorsiva di qualsiasi testo (di nuovo: artistico o letterario poco importa) nasce da meccanismi aggregativi che sono comunque di tipo spiccatamente retorico, e dunque, in ultima analisi, linguistico".

25. Bohigas ed. 2005: vv. 45-46.

26. Per il senso metaforico del foedus coniugale e della “viduïtat”, vid. Gómez-Pujol (2008: 66-67): “el poeta simplement planteja un símil: només aquells qui hauran perdut la muller que estimaven podran jutjar, en part, el dolor de l'amant que se sentia unit en cos i ànima a la seva estimada, com si fossin 'duo in carne una', com si fossin marit i muller. El vincle sagrat del matrimoni fóra aleshores la metàfora d’un amor sublim extraconjugal”. E ancora Gómez (2008: 6I62): “Els 'Cants de mort' lamenten la pèrdua d'una dama amb qui el poeta mantenia una relació amorosa com la descrita en 'Veles e vents han mos desigs complir' (XLVI): un amor recíproc i tan íntim que es mesura amb el foedus coniugale i en transcendeix els límits fins a desfiar la mort", di qui "l'assistència del poeta a l'agonia de l'estimada i, sobretot, la voluntat de compartir el seu destí espiritual al més enllà, i corporal a la sepultura, fins al dia que la resurrecció de la carn farà possible el seu anhel de fusió en cos i ànima”. Tant’è che, a riguardo, è da ricordare un passo, in particolare, di Veles e vents: "En lo perill no·m caureu de l'esment, / ans votaré hal Déu qui·ns ha ligats, / de no minvar mes fermes voluntats / e que tots temps me sereu de present” (Bohigas ed. 2005: vv. 2I-24), con la relativa interpretazione di Badia (I993: 228). Quanto visto si pone in evidente continuità con la Istòria corelliana, dal momento che in essa, sin dall'inizio, il lícit matrimoni (il foedus coniugale), facendo tutt'uno con la honestat, è un concetto-valore guida ripetutamente evidenziato sia dai due giovani che dalla nutrice. Infatti, Morros Mestres (2013: 235): "Para ese tratamiento del amor de los protagonistas [Corella] podía haberse inspirado en la fábula de Céix y Alcíone porque sus personajes son esposo y esposa desde el inicio de la acción. Pero tampoco cabe descartar que hubiera conocido (aunque sea parcialmente) el epilio griego por ser Museo el único autor antiguo en plantear abiertamente el amor conyugal entre nuestros amantes”. 
e lo meu cors, ans que la vida fine,

sobre lo seu abraçat vull que jaga.

(Bohigas ed. 2005: XCII, vv. 245-46)

Del resto, è comune opinione che la situazione erotico-sentimentale oggetto del canto rimandi ai temi nucleari del XLVI (Veles e vents), e che Veles events, a sua volta, si nutra tra le altre cose dei signa e delle res dei miti di Ceice e Alcione e di Ero e Leandro (Gómez-Pujol 2008: I86-87 e ibid., I9O, n. 22; Gómez 2008: 6o ss.). La tempesta, la resistenza eroica dell’io lirico, il sacrificio estremo, il naufragio, il destino degli amanti nell'aldilà, il mantenimento in eterno del foedus ne sono alcune delle direttrici di senso comuni. Sicché se parlavo di "memoria letteraria", e se ho insistito particolarmente sull'episodio conclusivo, comprendente le ultime due sequenze (Aribà lo cos de Leànder mort a la terra e Lo plant e mort dolorosa de Hero sobre lo cos de Leànder), è perché soprattutto in esso si addensano immagini, associazioni, analogie mentali, filate sulle tematiche suddette, che si saldano in una nuova rete di relazioni e funzioni, convertendosi in un centro di irradiazione di pathos che investe tutta l'orditura discorsiva. In sostanza una mise en abyme della stessa memoria culturale.

Guardiamo Hero. La morte dell'eroina col "ferro" di cui non mancano, peraltro, testimonianze, segnalate più o meno di recente, nella tradizione ispanica e italiana, ${ }^{27}$ se ha indubbiamente come modello soggiacente quella di Tisbe, è indubbio che sia un "gesto" che concentra, e al tempo stesso sprigiona, anche il pathos degli ultimi istanti di vita di una Didone, di una Phedra (di Seneca), di una Canace; nonché lo sgomento di Fiammetta quando, in preda allo sconforto, passa in rassegna varie modalità di suicidio,

E prima mi occorsono ne' pensieri li ferri, a molti di quella [la morte] stati cagione, tornandomi a mente la già detta Elissa partita di vita per quelli. (Delcorno ed. I994: VI, I6, 5),

evocando a sua volta la stessa amara rassegna di Fillide:

hinc mihi suppositas immittere corpus in undas mens fuit, et, quoniam fallere pergis, erit. Ad tua me fluctus proiectam litora portent occurramque oculis intumulata tuis.

...

Saepe venenorum sitis est mihi, saepe cruenta traiectam gladio morte perire iuvat; colla quoque, infidis quia se nectenda lacertis praebuerunt, laqueis implicuisse iuvat.

(Fedeli ed. I999: II, vv. I33-42)

E se, alla fine, la Hero corelliana, diversamente dalla Ero della "vulgata", non muore precipitando dalla torre in mare ma solo dopo aver raggiunto e abbracciato il corpo di Leànder, ciò accade, come sappiamo, perché il testo si chiuda con la mise en scène di una ritualità "tristaniana" di morte,

27. Nel Libro de las veinte cartas e quistiones di Fernando de la Torre (composto entro il I446) si legge: "e como lo mata la tormenta, e asi muerto, lo lieua al pie de dicha torre, e como ella lo vee, se mata con un espada.” (Paz y Melia ed. I907: I36). Su ciò, cfr. Morros Mestres, 2OI3: 236, n. 66; Pujol, 2OI3 (benché consideri la testimonianza un caso, unico nella tradizione iberica, "molt poc significatiu": I78, n. 65); Annicchiarico 20I4: 3I3, n. 24. Per le testimonianze italiane di una Ero che muore "collo suo proprio coltello", vid. Pujol, ibid., I77. 
all'interno della quale la protagonista possa ricavarsi il tempo necessario per un planctus. ${ }^{28} \mathrm{Al}$ contempo sappiamo che, a prescindere dall'attrazione esercitata da Tisbe, da tempo immemorabile spunti tematici comuni, giochi di rifrazione, simmetrie e specularità, nonché il "ritorno" di matrici topico-retoriche hanno fatto sì che la vicenda e la morte di Ero e Leandro, legata già in origine da relazioni di affinità a quella di Laodamia e Protesilao, di Ceice e Alcione ${ }^{29}$ sia diventata punto di convergenza di nuovi intrecci tematici, metaforici, figurali.

Nel dire questo, penso a quei dettagli riguardanti gli ultimi momenti di vita della Hero corelliana che, per quanto diversi rispetto alla vulgata, hanno essi pure dietro di sé una tradizione; la tradizione "profana" di una Ero che raggiunge la riva, che si lancia sul corpo di Leandro, che lo inonda di lacrime, che lo asciuga, che muore di dolore, o che si uccide..$^{30} \mathrm{E}$, nel contempo, la tradizione "religiosa", segnatamente quella bimillenaria dei planctus virginis, centrata sullo strazio della mater dolorosa; una mater, infatti, che porta nel cuore e nell'anima un metaforico "coltello di dolore", ${ }^{31}$ che lava con le lacrime il sangue del figlio, che chiede di essere sotterrata col figlio, che compone l'epitaffio. Dunque, altrimenti detto, la mater dolorosa della quale Corella dà una rappresentazione a tutto tondo nella sua stessa Oració a la sacratíssima Verge Maria, i cui legami intertestuali per

28. Vid. Martos (200Ib: 254): "I la tradició la fa saltar a la mar des de la torre i morir així", giustamente notando (ibid., 254-55) che la stessa Istòria implicitamente lo ricorda: "No tardara sobre lo cos mort la ja quasi morta donzella, saltant de l'alta torre, acabar de matar-se, sinó que volia, encara vivint, la boca freda besar de Leànder." (1l. 42I-23). D’altronde, già nell'epistola ovidiana, Leandro, presagendo scenari futuri, così scrive a Ero: "Optabo tamen ut partis expellar in istas / et teneant portus naufraga membra tuos. / Flebis enim tactuque meum dignabere corpus / et 'mortis, - dices, - huic ego causa fui'”. (Fedeli ed. I999: XVIII, vv. I97-200). Ma su ciò, vid. le successive note 29 e 30.

29. La morte divide in entrambi i casi la coppia. In entrambi, la protagonista femminile riceve in sogno l'apparizione del coniuge esangue o esanime, e in entrambi medita il suicidio; uccidendosi effettivamente (Laodamia), o ricevendo dagli dei pietosi la metamorfosi, insieme al coniuge, quando sta per farlo (Alcione). Morros Mestres (20I3: 225 ss.) e Pujol (20I3: I7̧O n. 43) opportunamente rilevano che già l'Ovide moralisé intreccia e contamina il mito di Ero e Leandro con quello di Ceice e Alcione: "el poeta francés ... inicia de este modo una contaminación entre las dos fábulas que autores posteriores llegaran a ampliar (Nadal, Corella, Tasso y Boscán)” (Morros Mestres, ibid. 227). Nello specifico, Pujol (ibid., I59-69), partendo dall' analogia tra l'episodio (chiave) della visione dello sposo ricevuta in sogno da Alcione e l'apparizione dell'ombra di Leànder davanti a Hero, commenta le vicissitudini parallele delle due eroine e dei rispettivi partner. Per le prime: lo struggente tentativo di entrambe di abbracciare il marito / l'amante (già morto) nel sogno/ visione; il pianto, la disperazione; il desiderio di “morire insieme”; la speranza di finire in un'unica urna, con un'unica iscrizione; (con l'arrivo della salma restituita dalle onde) l'abbraccio finale. Per i secondi, l'analogo destino: ingoiati dai flutti e finiti, entrambi, col nome dell'amata sulla labbra.

3o. Il succitato contributo di Pujol (2OI3: I7̨ I ss.) segnala, e commenta, fonti e modelli ai quali far risalire i momenti finali della storia e le caratteristiche della morte di Hero: "aproximació a la riba, descoberta del cos, lamentació i llàgrimes que mullen el cos mort, i suïcidi amb un coltell”. A iniziare dal carme I5.9 di Baudri de Bourgueil e dalla Leandreride: "En Baldric de Bourgueil, Hero abraça, eixuga, besa i plora Leandre llargament. A la Leandreride, baixa fins a la platja i es lamenta amb profusió abans de morir de dolor abraçada a Leandre.” (I7I); su ciò, vid. anche Morros Mestres (2OI3: 22I; Annicchiarico 20I4: 3I3). Per passare a testimonianze variamente significative della tradizione italiana: dal volgarizzamento fiorentino trecentesco delle Heroides di Filippo Ceffi (172), al Teseida, all' Elegia di Madonna Fiammetta (I7I ss.); a riguardo, vid. anche Martos (2005b); Annicchiarico (20I4: 3I3). Per proseguire, ancora, con uno sguardo alla tradizione francese (da l'Ovide moralisé, alla Cité des dames di Christine de Pizan). Riporto la conclusione dell'excursus: "Tots els autors que fan plorar Hero a la platja han de resoldre'n la mort d'una manera diferent de la canònica (ofegada, de dolor o amb un coltell), i necessàriament ha de morir abraçada a Leandre. Per això és inevitable pensar en Iseut i Tristany; també ho feia Boccaccio. Però la solució cruenta de Corella s’ha relacionat des de Miquel i Planas amb la mort de Tisbe, que, al seu torn també deixa traces sobre el cicle de Tristany" (Pujol, ibid., I74-75).

3I. Attenendomi alla tradizione catalana, cito a titolo d'esempio, un paio di passi della Istòria de la Passió: "Estava, donchs, prop la creu dolorosa, / travesant-li l’ànima coltell de dolor" (Garcia Sempere ed. 2002: st. 3I9, vv. 3454-55); "Hon sou, Simeon, que ara·m recorda / ... La vostra paraula és ara complida / car per lo mort fill que tinch yo present / coltell de dolor me té ja ferida, / coltell de gran pena me pena la vida, / coltell la mi.ànima trespasa·b turment." (ibid., st.

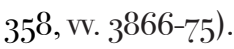


l'appunto con la Istòria de Leànder y Hero, come già ricordavo più su, sono ben noti. ${ }^{32}$

Ad essa è il momento di dedicare qualche osservazione, riportandone alcuni segmenti testuali tratti sia dalla preghiera, l'oració, recitata da un "noi" rappresentativo della comunità dei fedeli, sia dal planctus della Vergine. Con i corsivi evidenzio le parole-tema-immagine e i moduli sintatticoretorici che rimandano, in un gioco di richiami e rispecchiamenti, alla Istòria de Leànder y Hero:

ver Déu e hom, lo fill de Déu e vostre

jau tot estés en vostres castes faldes. (ll. IO-II)

Ab fonts de sanch regà lo verge strado hon, chich infant, lo bolcàs ab rialles; $y \cdot l s$ vostres ulls estil.len tan gran aygua, que pot lavar les sues cruels naffres, fent ab la sanch un engüent e col.liri d'inffinit preu, per levar-nos les taques (11. I2-I7)

Lo vostre cor partit ab fort escarpre, de gran dolor vos mostra tan greu plànyer que.ls seraffins ensemps ab tots los àngels mirant a vós planyent, aprenen dolre. (ll. 20-23) ${ }^{33}$

O, Fill tot meu!, hoÿu a mi que us parle; que.n lo dur pal haveu hoït lo ladre, puix no voleu que de present yo muyra, estiga.b vós tancada.n lo sepulcre. Yo us acollí en lo meu verge ventre, ara vós, Fill, rebeu-me dins la tomba, que no.s pot fer entre.ls vius yo conversse, puix que vós, mort, és ja ma vida morta. (1l. 28-35)

Cobrir vos ha lo mantell qu a mi cobre e si no us par vos baste tal mortalla, la mia carn, que viu haveu vestida, no us sia greu que, mort, encara us cobra. (11. 40-43) (Garcia Sempere ed. 2002: 449-5o)

Dove più di un particolare è degno di nota. Innanzitutto il lemma estrado che genera ulteriori associazioni di idee e immagini. Ricorrente in Corella (talvolta in combinazione con fald $a^{34}$ ), e dalla densa valenza semantica, nella Istòria esso evoca il lectulus elegiaco, luogo della passione-fuga dal mondo, e, nel contempo, della assenza/vuoto/rimembranza struggente. Come dire, il grembo di Hero che, nella macrometafora della navigazione amorosa (en la taraçana del estrado de Hero, 1. 23I), è il porto dove approda, attratto dalla calamita-Hero, il nocchiero-nave d'amore. Ed è il

32. Vid.n. I4.

33. In riferimento a vos mostra 1. 2I (nos mostra negli altri editori da Miquel i Planas ed. I9I3: 409 in poi), vid. l'annotazione di Garcia Sempere, ibid., 497 .

34. estrado de la sua falda: in La Istòria de la gloriosa Santa Magdalena (Miquel i Planas ed. I9I3: 328, 1. 637); in Tragèdia de Caldesa (Rico ed. 1984: 23, 1.27); estrado de la vostra falda: in La visió a la porta de la Senyora Nostra de Gràcia (Wittlin I995: 268). Per i significati metaforici assunti dal lemma nelle sue occorrenze, mi permetto di rinviare a Annicchiarico 2006: 67-69. 
porto che, nella sua significanza erotico-etico-allegorica, sussume in sé tanto l'idea del desiderio, emblematicamente consumato, manco a dirlo, nella dimensione del morboso sobramar, quanto l'idea della luce della salvezza. Dunque, concentra in sé la duplicità insita nella valenza metaforica dell'isola stessa - beata e maledetta / inferno e paradiso - e del suo pendant isotopico, l'alta torre/ faro/luce (Annicchiarico 20I4: 298-300).

Altro dato evidente sta nel fatto che è lo stesso campo semantico-metaforico della navigazione (porto, calamita-ago calamitato, "taraçana", nave) a rimandare all'impiego massiccio proprio della tradizione passionista, di nuovo, di figuranti marini chiamati a rappresentare simbolicamente la Vergine e il Figlio. Talché, cade opportuno, prima di tornare specificamente al planctus della Oració, citare campioni testuali rappresentativi sotto questo aspetto. Da Lo quart:

es arbre de la nau de la santa sgleya lo cors de iesus es la vela en aquesta nau es mester ques embarquen los qui volen pasar al port de la eterna gloria (Lo quart del Cartoxà I495, facsímil I998: $\mathrm{LXXIV} v$ ).

poi, dalla Vita Christi (Isabel de Villena):

del Fill meu, qui en aquesta gloriosa creu ha celebrat lo gran misteri de la redempció humana he l'ha feta nau e passatge molt segur per anar al regne seu.

(Escartí ed. 2OII: CCLXXXIV, 558)

E ancora, infine, dalla Istòria de la Passió, dove, come è noto, tale metafora è molto frequentata (Hauf I990: 318; Garcia Sempere ed. 2002: 36r, n. 333):

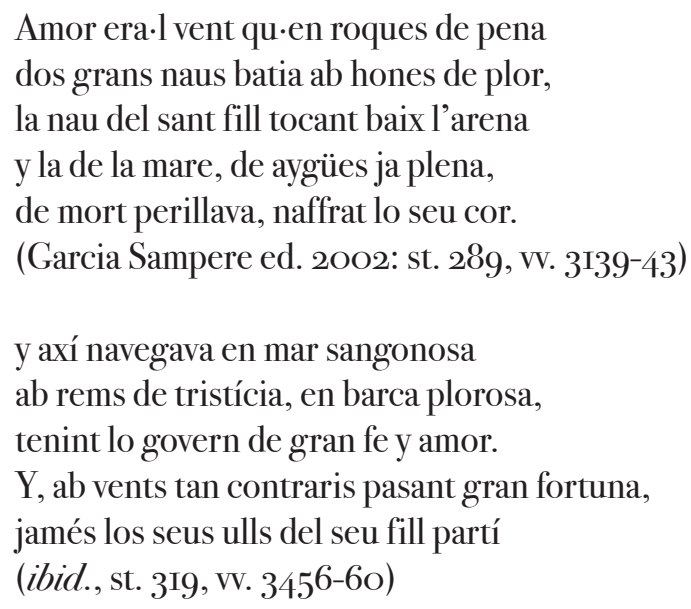

E cito ancora un esempio, sempre dalla Istòria de la Passió, compreso peraltro tra quelli già segnalati da Hauf (I990: 3I7-I8), in cui la croce e Cristo sono raffigurati come costituenti di una "nau carregada" e "cada part del cos crucificat correspon a una part del vaixell" (ibid., 3I8):

estava surgida en port de bonança

la nau carregada de nostra sperança

ab caxa tan rica de tèber sagrat.

Tenia per gàbia, per lum y canela

lo cap, ab corona y ab ulls tan devots;

lo cos era l'arbre ab digna cautela,

los braços l'antena, ell, Déu, rica vela

brodada de sanch, de plagues y açots. 
(Garcia Sempere ed. 2002: st. 35I, vv. 3796-3803)

Qui, appunto, spicca il sintagma la nau carregada che rammemora le parole di Leànder: "e lo meu cos és la fusta hon l'ànima de Hero mia, de amor carregada, ab los rems dels meus braços passa" (11. 224-25). Le quali a loro volta riecheggeranno, alla fine del testo, in un passaggio del pianto di Hero: "Per mi del teu cos havies fet galera, portant a la rriba de Cestos la mia sobre totes estimada mercaderia; e passant fortuna vàlida, has lançat lo càrrech de la tua ànima, la qual lo teu cos sostenir no podia, per lo pes que, de la mia amor carregada, portava" (1l. 459-62). Ed entrambi i passaggi, di lui e di lei, lasciano vedere in filigrana, e sempre con l'idea dell'anima verius est ubi amat quam ubi animat nello sfondo, il motivo amoroso-cortese della nave d'amore piena di "mercanzia preziosa": ne ricordo, a riguardo, due occorrenze petrarchesche: "nave di merci precïose carcha" (Bettarini ed. 2005, II: CCXXXV, v. 6); "una nave ... ella carca di ricca merce honesta” (ibid., CCCXXIII, wv. I3-I8).

Ora, tornando alla Oració, dopo questa parentesi su motivi e stilemi correnti all'interno della navigazione come figurante metaforico complesso, meritano ancora qualche osservazione i richiami verbali, e le corrispondenze tra segni e immagini, individuabili tra la com-passione della Vergine e lo strazio di Hero. Un gioco di proiezioni, o allusioni, il cui effetto è quello di suggellare, una volta di più, la dimensione totalizzante assoluta dell'amore - dell'amore-passione nella Istòria - in simmetria con l'immedesimazione-annullamento del sé alienato nell'altro. Mi riferisco alla pioggia di lacrime e sangue, alle parole, ai gesti, ai pensieri da stabat mater di Hero; alla sua copagorja "coltell de dolor" -, e alla com-passione, contestualmente suscitata nell'universo mondo ("lo cel clar, la nit quieta, los ayres, los elements e Diana, los planets e les esteles ... los peixos e los oçells”, 11. 440- 42). Ma, in particolare mi riferisco alle strategie retoriche di alcuni passaggi chiave delle ultime sequenze e, in specie, dell'ultima, comprensiva peraltro del pianto di Hero, la cui trama verbale è punteggiata da riprese paronomastiche, parallelismi, antitesi, e ossimori esasperatamente giocati sul binomio vita-morte. Come è dato vedere correntemente, appunto, anche nei planctus virginis. 35

Così infatti dice la Vergine, o si dice della Vergine (Istòria de la Passió):

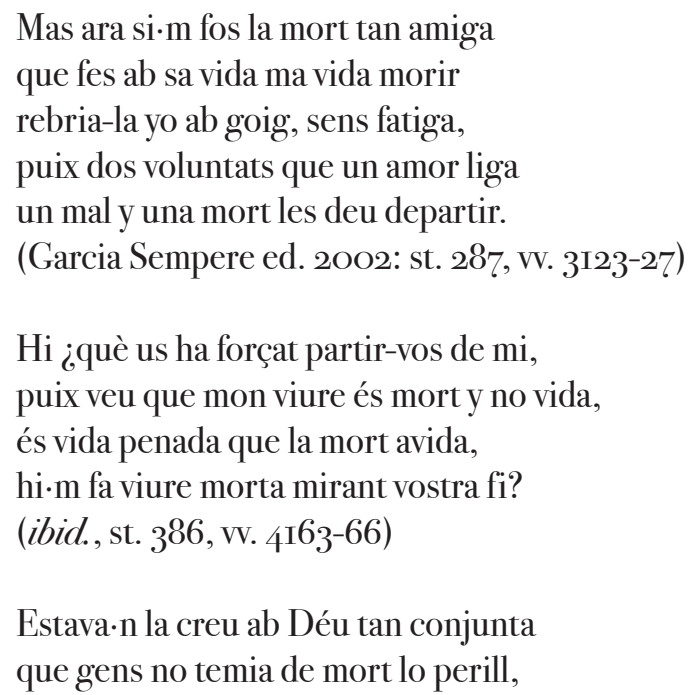

35. Valga, per tutte, la testimonianza del già citato Liber de passione Christi: "Imo strata jacens pallebat quasi mortua, vivens vivebat, moriens vivensque moriebatur, nec poterat mori, quia vivens mortua erat” (PL, I82, cl. II38 A). Sui "violenti ossimori”" del brano, veicolo di "lancinanti imagines agentes", vid. il fine commento di Bologna (20o6: 226). 
ans molt més amava, sens ser may desjunta, morir y en lo marbre ab ell ser conjunta que viure sens viure lo seu amat fill. (ibid., st. 32O, vv. 3469-73)

\section{E così Lo quart:}

com se pot fer mon fill que yo viure puga mirant morir la mia vida ab quina vida yo puch viure qui ab la tua per la tua hi en la tua vivia $(64 r)$

e a mi mare tua quem dexes dexam fill meu lo cors puix de mi las pres dins lo meu verge ventre ara sies content que en les mies castes faldes repose e tu pren lo meu sperit que dins lo teu cors stiga que en lo meu algun repos no troba treballare fill meu quand te posaran en lo sepulcre que axi fort los dos nos emboliquen hi en les teles nos strenguen que ab la mia anima los dos cossos vixquen vius e morts dormiran en lo sepulcre vius per la mia anima morts per absencia de la tua sera de nosaltres una persona viva ensemps e morta $(64 r-64 v)$

o fill meu dulcissim ... hou ara mort la tua mare viva que sobre totes les coses que desijar se poden desija ab tu esser morta ... que stiga ab tu dins lo sepulcre tancada fins que lo teu cors e la mia anima resuscite ... nis moura mes quel fill mort la mare viva ... cubert ab lo mantell de la mia pobra roba $\mathrm{e}$ si axi no baste scalfar te les mies purissimes sanchs e carn que deu viu cobrir te pogueren ara mort home te serviran per mortalla ( $7 \mathrm{O} r-7 \mathrm{O} v)$,

e così Hero:

e axí, los cossos morts, abraçats, estaran en un sepulcre, e nosaltres, en dolor vivint, juntes en una pena. (11. 404-05)

¿Quin plant sobre.l teu cos puch yo, encara viva, mirant a tu mort per mi, dignament plànyer? ... Donchs viuré yo, perquè la tua mort per mi causada dolgua; e prest per tu morré, e per tu no seré plorada, ab tot que per tu muyra: hi és molta rahó, puix tu primer per mi has perdut la vida. (ll. 450$56)$

hi estés, fret, banyat hi mort, tens les espatles en aquell loch hon tenies los peus quant, viu, me abraçaves. (11. 463-65)

E così ancora, leggiamo di Hero, nel passaggio chiave, già commentato, dei baci e delle lacrime sugli/negli occhi di Leànder:

hi ab les mans tremolant los ulls de Leànder obria, los quals primer ab la boca hi aprés ab los ulls besant axí de abundants làgremes omplia, que semblava Leànder, encara mort, plorant la dolor de la sua Hero viva, planyent... deplorava (11. 429-32),

fissando una immagine che rimbalza su quella finale, lapidariamente sigillata dal polittoto mort/ moria: "espirà la miserable Hero, entre.ls braços frets de aquell mort per qui moria” (1l. 492-93).

Un passaggio chiave, dicevo; dove l'allitterante gioco paronomastico omplia - plorant-planyent - deplorava marca la simmetria speculare e drammatica delle azioni dei due protagonisti: pianto e lacrime dagli occhi di entrambi, reciprocamente invocantisi, e con un Leànder cadavere che "en la boca morta aquell gest guardava, ab lo qual lo nom de Hero se pronunçia” (1l. 3OI-O2). E il momento in cui il topos dell'immagine dell'amata impressa sul volto dell'amato diventa, declinata quasi $a$ lo divino, il segno della com-passione di Leànder per il dolore di Hero. Compassione che è, a sua volta, 
signum dell'immedesimazione dell'uno nell'altro e del perdurare del "privilegio degli amanti" oltre la vita. ${ }^{36}$

Dunque, parlavo di un centro ideale, diegetico e metaforico, rappresentato dalla scena finale del pianto e della morte di Hero, come riquadro centrale di un retaule, intorno al quale si dispiega nei comparti laterali la narrazione degli eventi antecedenti. Ora aggiungo che, riflettendo sugli equilibri interni che la macchina diegetica attualizza tra le res e i personaggi, e interrogandomi sul possibile istituirsi di ciascuno di essi a cifra rappresentativa di ciascun piano narrrativo, la storia appare articolata in tre fasi ideali, delle quali, la iniziale e la finale appaiono dominate, rispettivamente, dalle due protagoniste femminili: la nutrice e Hero. La prima, ligia al suo ruolo tradizionale, ovvero fedele al modello ovidiano-senechiano-boccacciano, è il baluardo di difesa della honestat (parola tematica insistente soprattutto, appunto, nelle prime sequenze). È dunque, la voce della ratio, della virtù, della fama, contro il furor della passione che ha investito la sua pupilla. Protettiva, solidale, interprete puntuale del nome che porta, ${ }^{37}$ Latíbula garantisce la propria complicità ai giovani amanti, non soltanto per un impulso affettivo ed emotivo, ma anche perché fa suo il dispregio di Hero per l'odioso pretendente (Exosus) e ne condivide, del pari, la stima per Leànder ("E si tu no vols aquest jove Exosus, a qui mèritament tan gran oy portes", 11. I42-43; "Leànder, a qui mèritament tant ames", 1. 37I). Di più, è sull'intesa fra donne che nasce e si consolida il rifiuto da parte di Hero di accettare le volontà del padre: un padre, "anticortese", per nulla sensibile alle virtù morali, ed esclusivamente attratto dai beni materiali ("Però, atenent Austerus als miserables béns de fortuna, entre.ls altres, per a gendre, elegia un jove desert de béns naturals e morals, perquè en grans riqueses abundava", 11. 78-80).

Nel mezzo, un mezzo naturalmente ideale, si colloca il sacrificio estremo, dell'amante "estremo", consumato in una tempesta che è tanto tyche quanto punizione divina, tanto dannazione quanto salvezza. Amore estremo, abnegazione estrema, martirio estremo: tutti e tre eletti a dimostrazione della fragilità dell'io di fronte alla propria indomabile passione, vissuta tuttavia nella dimensione nobile e gentile di un antico sistema di valori, e della impotenza, pur tuttavia eroica, dello stesso io di fronte alle passioni altrui. Le passioni, evidentemente, riassunte dagli schemi mentali, materialisti e riprovevoli, di un padre istituito ad antagonista perfetto di quelli stessi valori. D’altra parte, si tratta di un padre così ignobile, e di un esercizio dell'autorità paterna così egoistico, da fare della colpevolezza trasgressiva di Hero un caso straordinariamente pietoso, e della sua sofferenza un dolore “cosmico". E ciò, con buona pace del pubblico femminile, nel quale Corella individua il suo orizzonte privilegiato di attesa e dal quale si attende una immedesimazione-commiserazione pietosa che, necessariamente, è “com-passione” per il gesto finale, estremo ed eroico stavolta al femminile, di Hero.

36. Per l'immagine dell'amata che l'amante porta impressa anche da morto, vid. Jordi de Sant Jordi, Jus lo front port vostra bella semblança: "ans, quant seray del tot fores d'est segle, / çels qui lo cors portaran, al sepulcre / sobre me faç veuran lo vostre signe.” (Fratta ed. 2005: IX, vv. 6-8; vid. anche Riquer-Badia ed. I984: I69-7I, n. 5-8) e Comendador Escrivá: "que, al tiempo qu’e de perdella, / dexará forma en mi gesto / del vuestro que irá ab ella" (Ravasini ed. 20o8: 26, vv. 7-9; vid. anche pp. 50-5I). Per il più ampio tema dell'identificazione dell'amante nell'amato (topos platonico ripreso dai Padri, per il quale rinvio a Serés I996: I2I ss.), vid. Bettarini: "Il verbo specifico quasi tecnico della virtù unitiva dell'amore è trasformare ... verbo che, su concetto neoplatonico, è già formalizzato nella tradizione dei mistici entro formule specifiche dell'amore estatico in un oscuro intreccio dell'amato e dell'amante, sull'auctoritas di san Paolo" (ed. 2005: I, 450; vid. anche II, 999, n. I4; I589, n. I28). Sul tema, a proposito di Ausiàs March (XLV: "reprenen mi perquè·m tresport en altre”, Bohigas ed. 2005: v. 3), vid. Gómez-Pujol 2008: I72, n. 3-4, con altri rinvii interni. In questo contesto, valga anche un esempio offerto dal Corella lirico (Cor crudel): "puix que, dins mi, vos tinc en bella forma, / treta del viu en perfeta figura, / ab les colors sobre el fresc, i l'empremta, / que ni la mort, ni el temps, ni l'altre segle, / raure no us pot, ni del riu Letes l'aigua." (Martínez ed. 1994: 54, vv. I2-I6).

37. Per l'interpretatio nominis della Istòria, vid. Pujol (2OI3: I8I) e Annicchiarico (2OI4: 3OI-O2). 


\section{Testo}

Criteri di edizione: Assumo a fondamento dell'edizione il ms. Maians ( $V$ ) molto più stabile e accurato del Jardinet de orats $(O)$, latore di una lezione, anche in questo caso, penalizzata da "la mala caligrafia y la poca escrupolositat de la copia" (Miquel i Planas i9I3: XXVII; Torró

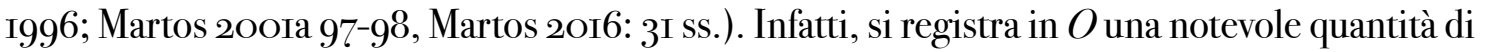
banalizzazioni, guasti meccanici, fraintendimenti ed omissioni, a fronte di una modesta presenza di lezioni equipollenti o comunque plausibili..$^{3}$ Rispetto e conservo la lezione di $V$ fin dove sia accettabile. L'Apparato raccoglie le lezioni di $V$ non accettate, o oggetto di emendamento, e le varianti del Jardinet de orats (con esclusione di quelle esclusivamente grafico-fonetiche). In linea generale, va da sé che per le varianti plausibili o adiafore, resti a monte quello che si è ipotizzato, e congetturato, negli studi degli ultimi decenni, sulla possibile presenza nel tràdito corelliano di varianti d'autore ascrivibili a momenti redazionali distinti (Annicchiarico 1996; 2006: 7I ss.; Miralles I998; Martos 200Ia: 97).

Le note di carattere ecdotico poste a corredo del testo concernono i casi in cui la constitutio textus richieda una segnalazione specifica o un momento di discussione. Riproduco fedelmente la grafia del testo-base, limitandomi a regolarizzare l'uso di $u-v$ e di $i-j$. Non segnalo in apparato i pochissimi casi in cui nella trascrizione di $V$ è stato necessario ripristinare la grafia $c$ (in luogo di $c$ ). Nella separazione delle parole, nella punteggiatura, nell'accentazione, nelle maiuscole e minuscole, nell'uso del trattino, e parzialmente in quello dell'apostrofo, seguo le norme del catalano moderno, indicando col punt volat le elisioni che oggi non hanno rappresentazione grafica.

38. Ritengo utile fornire, a titolo esemplificativo, una breve campionatura degli errori meccanici e travisamenti di $o$ a fronte della lezione corretta (fra parentesi) addotta da $V$ : [descreçió] destruccio 22; [viçiosos tractes] virtuos tracte 43; [d'onesta] de nostra 7I; [per a gendre] per apendra 79; [morals] mortals 79; [conpondre] compendre 262; [reclamant] clarament 279; [la sua veu] lavores 3І2; [crida] triada 325; [avorreria] avaricia 383; [atenta] atenia 44I. Quindi una breve esemplificazione di passi palesemente corrotti: [tardà Latíbula tornar] torna Latibula tornant I38-I39; [mire, és la estela a la qual] miren en la stella en la qual 223; [la entrada defenia] ja en terra defenia 282; [passarà molt tornarà] pensara tornara gayre 325; [passant la mar] pensant pessant la mar 373; [torre e, mirant per la lum escura de Diana] torre de Diana 4I3; [lauger... has pogut] Leander... es pogut 463. E, infine, una breve campionatura di lezioni accettabili o adiafore: [donzella] dona 9; [mia penssa] pensa 42; [criada] donzela III; [trista] plorosa I45; [dues] ditas I75; [acaminava] continuave I89; [iniqua sort] mia sort 2I4; [guardava] mostrave 3or; [de Apol·lo] del sol 323; [Leànder] animos Leander 329; [prudent esforçada dida] sforsada vella $355^{-3} 35^{6}$. 


\section{LA ISTÒRIA DE LEÀNDER Y HERO}

En la nostra mar Mediterrànea, en la província de Grècia, en les ylles que vulgarment l'Arçepèlech se nomenen, estan dues çiutats, Çesto hi Abidos, distants la una de l'altra espay de miga legua; lo qual espay la mar occupant veda les dues ylles sien una.

Estava en la ciutat de Çesto Hero, noble donzella, de alt enteniment, gràcia e bellea, que per tots aquells regnes ab claredat de ínclita fama relluhia; hi en la çiutat de Abidos estava Leànder de alta perfecció, seny e gentilea. Sols diferien que, Leànder de home, e Hero de donzella, singulars gràcies possehia.

\section{Com se veren Leànder hi Hero, e Leànder parlà ab la dida}

Era passat Leànder a una gran festa que, solempne, selebraven en la ylla de Cestos; hi, entre les altres donzelles, Hero sobre totes estava, de clara hi elegant figura, a la qual Leànder ab modesta y entristida continença dreçà la vista, que axí u disponia la iniqua Fortuna.

Ixqueren al encontre al mirar de Leànder los ulls de la graciosa donzella. E al hu hi al altre fon semblant ab vires de enamorada erba tenien les entràmenes travessades, e que $\cdot$ ls ulls, dels retrets de la $(26 r)$ nafrada penssa, entre si portaven secretes embaixades. E fon tan gran lo mal de aquesta primera vista, que al hu y al altre constituhí en penssament de soliçitut profunde.

$\mathrm{Ab}$ aquella major descreçió que amor estrema comporta, demanà Leànder de la tan estimada donzella, y Hero de Leànder, seguint aquella arreglada onestat que a la sua fama gens no ofenia. E sotliçitut de amor verdadera, a la qual res no li.s encobre, descobrí al enamorat Leànder que tenia Hero una dida, Latíbula, de la qual sola en egual de la sua ànima fiava. Treballà Leànder ab delitosa fatigua, mostrant altres negoçis lo portaven, pogués parlar ab la tant fiada vella; hi ab gest vestit de temor honesta, a semblants

2. ylles: per Sesto e Abido date come isole, vid. Annicchiarico (2014: 297-99).

Io. possehia: rispetto la lezione di $V$, come già i precedenti editori (Miquel i Planas: 95 ; Carbonell: ı67; Martínez: 97) e diversamente da Martos (200га: І5I; 20I6: 51; seguito da Escartí: II3) che legge possehien (emendando su poseyen di $O$ ) con la motivazione che "El subjecte són els dos enamorats” (20I6: 33). Il passaggio vuole evidenziare la singolarità assoluta dei ciascuno dei due protagonisti, rispettivamente come uomo e come donna; dunque, la lezione di $O$ si configurerebbe, piuttosto, come una facilior. Vid. le osservazioni a riguardo in Intr. pp. I62-I63.

26. Latíbula: come già Miquel i Planas (96, seguito da Carbonell: ı67 e da Martínez: 98), e diversamente da Martos (2оога: ı52; 20ı6: 53; seguito da Escartí: ıг3) che integra da O: la qual avia nom Latíbula. Benché sia pertinente l'osservazione "en presentar el pare d'Hero, Corella ho fa amb una estructura molt semblant: al pare, qui Austerus se nomenava” (Martos 20I6: 35), non necessariamente è da vedere in $V$ una omissione. 
paraules féu prinçipi:

"La fama de la tua honestat, lo assosech e gravitat de la tua edat antigua, bastarien los meus desigs ordenar, si a terme desonest se endreçassen. Hi, perquè veig la tua continença ja.m mostra no ab plaer les mies paraules escoltes, no vull en largues proses la mia dolor estendre: sinó que a tu, ànima de Hero, sia manifest dins los térmens de honestat altre bé en aquest món no desige, ni-m és possible desigar pugua, sinó que, ensemps catiu e marit, en los braços de tua criada ma vida se allargue. Hi a tu, benaventurada dida, a qui ella tant mèritament ama, ofir los béns, la persona e la vida; que, puix és tot de Hero, la rahó vol ab les altres sues joyes ho tingues en comanda”.

"De la tua discreçió, afable, graçiós jove - respòs la discreta vella - tinch la mia penssa per admiraçió sospesa, que.ls actes de virtut vulles enlegir, cobrint-los ab vel de viçiosos tractes, semblant a.quells que la fruyta del seu ort més saborosa gusten, si per les parets, com a lladres, la prenen. Si tu, axí com dius, lo que rahonablement se deu creure, dins los límits de honestat desiges Hero, ma criada, muller tua vixqua, puix est tant prudent en elegir, no u sies menys en proseguir lo que virtuosament desiges. La mia criada hi senyora té virtuós pare de gran prudènçia, mare onesta de clara e virtuosa fama, parents en gran nombre y estima, ab los quals honesta(26v)ment pots tractar lo que demanes. Si tant, com dius, mèritament la estimes, fuig no solament cosa desonesta, mas tot lo que a desonestat pot tenir semblança; que, si per altres camins venies al terme que desiges, a tu mateix faries gran ofenssa, en lo temps que per muller e senyora la possehiries".

\section{Partí's Leànder de la çiutat de Cestos}

Partí’s Leànder de la discreta vella, ab penssament de sotliçitut trista com poria de Hero tractar lo matrimoni, çerquant tots aquells camins que al desigat terme portar lo podien. E, per altra part, la honesta donzella vots e prometençes als déus prometia, li fossen tant favorables que a Leànder per marit li atorgassen.

Espay de un any passava que Leànder, desdenyat del matrimoni, ab esperança perduda per lo camí de virtut ni per força de amor lo seu voler pogués atényer terme, delliberà de la vista de Hero un poch espay apartarse, passant la vida trista, e-sperar lo temps lo qual grans negocis termena. Hi partint-se de Cestos, los ulls endreçats a la riba e més a la casa de Hero, dins si mateix, que.ls altres no u hohissen, parlant murmurava:

43-44. semblant a.quells que la fruyta del seu ort més saborosa gusten, si per les parets, com a lladres, la prenen: nel quadro del Nitimur in vetitum semper, cupimusque negata (vid. Walther I982-86: I6956; Tosi I993: 419-20), valga, per tutte, la testimonianza veterotestamentaria dei Proverbi (9, I7: «Le acque furtive sono dolci, / il pane preso di nascosto è gustoso». 
"Tan gran dolor lo meu cor trist esquinça, que tinch reçel la mort prest no.m asalte, la qual yo tem perquè no $m$ faça perdre a vós, mon bé, per qui porte lo viure. E per ço fuig venir-vos al encontre; que.ls vostres ulls del mur d'onesta vida ab tempre d'or les fleixes de Cupido tiren, matant a tots los qui no us fugen.

Parlen a Hero molts matrimonis

(27r.) Era tan gran la honestat, seny, discreçió e bellea de la noble donzella Hero, que molts jóvens de alta sanch, ab grans béns naturals e de fortuna, al pare, qui Austerus se nomenava, del matrimoni de la ínclita filla sotliçitaven. Però, atenent Austerus als miserables béns de fortuna, entre.ls altres, per a gendre, elegia un jove desert de béns naturals e morals, perquè en grans riqueses abundava; que sovint s'esdevé que, per mostrar nostre senyor Déu dels béns de fortuna la pocha estima, permet sien possehits per aquells qui alguna virtut no posseheixen. No volia la entrestida donzella lo matrimoni, perquè no era de Leànder, hi encara perquè aquell la demanava a qui tot sol entre-ls altres, ella, encara no volgués a Leànder, avorria. Hi al pare donava resposta que, per al present, la volentat en matrimoni no la inclinava, escusant lo no ab algunes indisposiçions fengides de la sua delicada persona; callant la verdadera malaltia del amor de Leànder, sola per la qual la sua penssa, ensemps ab la persona, era malalta.

Conegué la dida la causa de la tristor de la criada

Atenia la prudent dida ab sotliçitut de gran amor en la vida de la honesta criada. Hi, atenent, mirava que una entrestida continença la cobria; e la color de la sua cara e magrea de tota la sua persona, ab contínua tristíçia sens manifesta causa, descobrien que algun penssament, en los retrets de la sua penssa aflegint, la turmentava; e continus sospirs, espirant, senyalaven lo foch que de l'amor de Leànder les sues entràmenes ençenia.

Axí portava la sua primera y estrema amor encuberta la trista donzella, ab pes de tant fexugua càrregua, que altre remey, sinó la vida perdre, de sos mals no estimava. Tant que, un jorn, a la hora que.l sol de nostra abitable terra cobrir-se volia, era pujada la plorosa donzella en una alta torre, de la qual (2ךv) los murs de la çiutat de Abidos, hon Leànder vivia, clarament se

95. ençenia: cremant encenia $O$; rispetto la lezione di $\mathrm{V}$, d'accordo con i precedenti editori, compreso Martos (200Ia: I56) e a differenza di Martos (20I6: 59) che integra cremant da $O$, con la motivazione che si tratta di uno stilema "genuí de Corella, que difícilment hauria generat el seu copista” (ibid., 33). Pur prendendo atto della ricorrenza del sintagma ("los sentiments del qual axí cremant encenia", Lo johí de Paris, Martos 2oora: 303, 1. 243), l’integrazione, non necessaria al senso, non è sufficientemente motivata. A monte vi è il principio che le due lezioni in concorrenza possono rappresentare "stati" del testo distinti. 
miraven. E sotlíçita la discreta dida de la dolor e tristura de la criada, ab suaus passos pujant, escoltava si la entristida Hero, estant sola, planyent se dolia; la qual, contemplant la çiutat de Leànder, ab làgremes que dels sseus ulls abundants corrien, en veu piadosa plorant deÿa:

"Del món no·m dolch, que ma vida vull perdre, perquè, del cos l'esperit ja delliure, pugua, volant, estar prop de Leànder”.

\section{Demanà la dida a Hero la causa de la sua tristor}

Encara més parlara la trista donzella, sinó que Latíbula, entrant per lo tarrat de la alta torre, no esperà més hoyr del nom de Leànder; e, acostant-se a la estimada criada, a semblants paraules féu prinçipi:

"La contínua tristícia que dins lo teu cor acollint comportes, en dan de la tua bella delicada persona, manifestament declara alguna estrema dolor la tua ànima greument turmenta. E no pensses quant perjudiques a la gran amor que·t porte; que ma vida ja no l'accepte sinó perquè a tu, axí com desige, pugua veure. ¿Com no.m descobres la causa d'on fas continent vols abandonar lo viure? Si és mal que remeyar no.s pugua, ¿per què, tenint-lo celat, magor lo aumentes, no donant loch per hon espire? Abandona, estimada filla, una part de la càrregua de tos enugs sobre mi, puix egualment ab tu l'accepte; e portem dos, ab carro de verdadera amistat, aquell pes que hu tot sol sostenir no poria. E, puix tens seguretat manifesta los teus secrets fora de la mia boca, sinó ab l'ànima, passar no poden, comunicant a mi de ton mal la causa, és forçat algun remey o descans atenygues, recolzant tan gran pes damunt lo pilar de la verdadera amor (28r.) que a tu, vida mia, endreçe”.

\section{Descobrí Hero a la dida l'amor de Leànder}

Un sospir, que dels retrets del cor de la plorosa Hero espirant partia, fon principi a semblants paraules:

"La honestat que de les tues mamelles, estimada dida, mamant he presa, ha tengut ma lengua muda, celant la tristor de la trista desaventura mia, esperant algun dia tu, per l'amor que $m$ m portes, ab gran instànçia me interrogasses; perquè.m paria no tant, responent, la mia honestat pendria injúria, car de moltes coses retrau honesta vergonya per ha interrogar, que lo

IOI. sotliçita la discreta dida: per la sedulitas propria del ruolo della nutrice, vid. Reed ed. 20I3: 248, n. 396 .

I2I. dopo secrets: que $V$, probabile trascorso di penna; lo espungo sulla scorta di $O$.

I29. La honestat que de les tues mamelles: per il motivo del "vecchio petto" della nutrice, vid. la Fiammetta boccacciana: "per questo vecchio petto ... dal quale tu prima i nutritivi alimenti prendesti” (Delcorno ed. I994: I, I4, I3), "io ti priego per questo misero seno onde tu li primi alimenti traesti” (ibid., VI, 2I, I); e, ancora, ivi (242, n. 29) il rinvio a Seneca, Phaedra (vv. 246-49), e a Ovidio (Met., X, vv. 39I-93). Altri riferimenti in Reed ed. 2013 (248, n. 39I-92). 
respondre comporta. La causa per hon ma vida se va a perdre és Leànder, al qual, dins los límits de honestat, yo per marit desige; e, si del terme de aquest desig ma vida se dessespera, no vull que mos mals sinó a mort desesperada passen”.

Un poch espay, los ulls endreçant a la lagrimant donzella, tardà Latíbula tornar semblant resposta:

I40 "Molt tart, o nunqua, de indiscrets principis fi pròspera s'espera. Si.l teu desig ab lo meu era conforme, estimada filla e senyora, hauries marit aquell qui, plaent a tu, a ton pare no desplauria. E si tu no vols aquest jove Exosus, a qui mèritament tan gran oy portes, dels altres poràs pendre algú a la tua volentat hi a la de ton pare conforme".

I45 "O gran desaventura mia! -respòs la trista donzella- que axí mon pare vol a Exosus per gendre, que de algun altre solament no u escolta. E ab tot que per si, encara que·n lo món fos sol, Leànder tant valgua, penssa, estimada dida, en comparació de Exosus, quant dins la mia penssa més perfet se troba. Però a tu ni vull ni puch negar, penssant en Leànder, egualment tots me desalten: per què a tots avorreixch, perquè no són Leànder; hi a Exosus avorreria, encara que tant no amàs a Leànder”.

\section{Conçertà la dida ab Leànder vingués a parlar ab Hero}

$(28 v)$ Fatigua seria de prolixitat enujosa recitant descriure les discretes honestes rahons que, per aconortar la trista criada, Latíbula parlant rahonava. Mas a la fi amor, que sobre les altres passions nostre enteniment enbenant ençegua, vençé a la prudent honesta vella, prometent a la enamorada criada per marit a Leànder, puix altre remey acceptar no volia; penssant no cometia gran erra per restaurar de la criada la miserable vida: hi a la enamorada donzella vençia l'amor de Leànder, hi a la prudent honesta i6o vella l'amor de Hero.

O gran ffollia creure que algun mal ab altre remeyar pugua, com sia determenada sentènçia qualsevol cosa aumenta si ab son semblant se ajusta! O benaventurats aquells qui, servint a Déu, per regla de virtuosa vida los seus manaments contemplen, e, qualsevol cosa los esdevingua, per no res la

I35-37. Come Fiammetta in risposta ai consigli della nutrice: "Adunque o la morte, o il giovane disiato resta per sola fine alle mie pene” (Delcorno ed. I994: I, I5, 8); ivi (243, n. 22) il rinvio a Seneca, Phaedra: "Haec sola ratio est, unicum effugiun mali: Virum sequamur, morte praevertam nefas ... Decreta mors est: quaeritur fati genus".

I50. tots me desalten: per què a tots avorreixch, perquè no són: diversa la lettura di Martos (2001а: 158; 2016: 63) che emenda tots me desalten e avorreixch perquè no són seguendo $O$ (tots me desaltan e avoresch perque no son). Conservo la lezione di $V$, con la interpunzione che è già nei precedenti editori (Miquel i Planas: IO2; Carbonell: I7ı; Martínez: IO3; Escartí: II : “desalten: perquè a tots ...”). In ogni caso, qualora si volesse dare al passo una maggiore fluidità sintattica, risulterebbe più "economico", e conservativo rispetto a $V$, l'emendamento di per què (che non è peregrino pensare come svista di anticipazione rispetto al successivo perquè no són) in e: tots me desalten e a tots avorreixch, perquè no són.

I6I. creure: om. in V; integro sulla scorta di $O$ (creura), d'accordo con i precedenti editori. 
I65 estimen, puix a Déu no sia ofenssa! Quant fóra millor a Hero soferir qualsevol tristor ho pena, ans que furtadament contractar de matrimoni ab Leànder! E si ans per dolor fos morta, contrastant a viçi, fóra la sua mort vida eterna, digna de premi, hi ara en los inferns no sentira aquella pena inhefable que.ls miserables desesperats eternament senten.

No passà espay de molts dies que, vengut Leànder a la ciutat de Cestos, ab la discreta vella conçertant acordaren com a la enamorada Hero presentar se poguera. E perquè delliberava Leànder ans la vida perdre que la fama de la estimada donzella ofendre, fon lo conçert que, al temps que la escura nit als furtats plaers loch abandona, Leànder nadant passàs aquell espay de mar que les dues çiutats separava; e que sens tarda, davant tothom, se partís de la çiutat de Cestos.

\section{Partí's Leànder de la çiutat de Cestos ab conçert e gran alegria}

Ab conçert e gran alegria de ésser escrita inpossible e de tenir callada difíçil, se partí Leànder de la çiutat de Cestos, mirant les aygües, la çiutat e la riba, e, sobretot, la casa de Hero, en la qual la sua ànima en alegre cativeri cativa (29r.) romania; hi, ab atenta sotliçitut considerant, atenia pogués recordar bon esme per a la nit, que nadant surgiria al port e terme que tant desigava.

O esforç terrible de amor estrema! Ni la fredor de l'aygua fonda, ni temor de la mar espantable, ni espant de les bèsties marines, ni reçel dels filats que.ls peixcadors estenien pogueren a Leànder retraure que, espay de un estiu, diversses vegades nadant passàs lo freu de la mar espantable, surgint lo seu cors e la ànima en les faldes de la sua Hero. E tant sovint aquest difíçil viatge ab esforç de amor acaminava, que li paria ja los peixos lo conexien e la mar li obria camí de calçigada senda. E, navegant lo novell mariner al contrari dels altres navilis, la nau del seu cos per les aygües discorria: que Hero, que era lo vent de les sues veles, en la proha, anant a la ylla de Cestos, semblant a caramida tirant lo portava; hi, tornant a la ylla de Abidos, aturant lo detenia.

O terrible força de amor, hi com fa lauger lo pes dels treballs que ab si porta! Axí feÿa lauger lo cos de Leànder, que als peixos nadant vençia; e les plomes de la promta esperança sobre l'aygua sostenint lo levaven, e tant la pròspera fortuna favorint lo afalagava, que los peixos e los oçells de la mar volant e nadant lo acompanyaven; e les esteles de tan gran claredat les rribes de Cestos il.luminaven, que la escura nit al migdia egualar se volia.

Axí acostuma afalagar la iniqua fortuna, quant del tot vol destrohir al qui engana, que de la sua adverssitat alguna part no mostra, perquè aquell a qui prospera contra ella no·s arme. O gran infortuni, que.ls molt prosperats en la més alta fortuna acompanya, que no tenint esperiènçia de adverssitat alguna, los pochs dans majors estimen, hi los grans sostenir no poden.

I68. digna: om. $V$; integro da $O$, come già i precedenti editori.

205. sostenir no poden: da notare, per completezza d'informazione, che la lezione omessa in un primo momento in $O$, e ripristinata da mano correttrice sulla riga già occupata dai 


\section{Clamà's Leànder de la yra de la mar}

Era arribat aquell egipçíach dia que la iniqua sort havia ordenat Leànder perdés a Hero ensemps ab la vida. Començaren los vents a moure les aygües més del que acostumat havien; hi aparellava's l'esforçat jove, acompanyat de l'amor $(29 v)$ que d'ell nunqua.s partia, al desigat viatge. E, venint a la riba de la mar furiosa, ab yrada veu contra la sua fúria blasfemant, deÿa:

"O gran desaventura mia, que tantes vegades com s'enterboleix l'aygua, lo meu cor se faça escur e tèrbol! En la adverssa fortuna conech lo bé que yo, ingrat, possehia quant, ab grans querelles, de la iniqua sort me clamava, que, sinó per l'aygua nadant, a la mia Hero acostar no·m podia. Ara, molt més fort cridant, contra la mar blasfeme, perquè lo meu cos no puch acomanar a l'aygua; e, per fortuna sobre totes pròspera, acçeptaria lo que ans estimava adverssitat estrema! O, sobre tots los vivints miserable! E com és poch espay lo que a mon voler contrasta, e tant major ma desaventura aumenta! Yo no demane nau, galera, ni altra fusta, ni veles, rems, timó, ni brúxola, ni mire la tremuntana perquè.l meu navegar s'endreçe, ni, per atrobar lo port del meu desigat viatge, desplegue dels mariners la carta: la lum que-n la torre per a mi ençesa mire, és la estela a la qual lo meu timó esguarda; e lo meu cos és la fusta hon l’ànima de Hero mia, de amor carregada, ab los rems dels meus braços passa. O mar de aygües amargues, per a mi més que als altres amargua!, un poch la tua fúria amança, fins que·n la rriba de Cestos haja pres alegra posta; e aprés, cobrada la fúria, fes difíçil la mia tornada, perquè ab justa escusa en les faldes de Hero la tua tranquilitat espere. Mira quant és poch lo que demanant te soplique: no vull que.l deute me absolgues, mas que un poch espay porrogant me comportes, e treta en terra la mia nau, en la taraçana del estrado de Hero, no la vararé en les tues aygües sinó ab gran temor; e lavors, ab discreta prudència, esquivaré los perills de la tua fúria, e, per molt que la vàlida fortuna dure, no blasfemaré contra les tues hones”.

Ensemps aquestes paraules parlant, Leànder la sua persona despullava; hi vestia's una camisa de les mans de Hero filada, cenyhint-se ab una correja, la qual sostenia una gentil copagorja; que altra arma nadant portar no podia. E acostant-se (3or.) a la furiosa aygua, cridant lo nom de Hero, acomanà lo 240 cos e la vida a la mar tempestuosa, la força de la qual no pogué vençre; ans, forçat, girà les espatles a les espantables aygües, tornant a la riba d'on se partia. Hi, estant de peus en la banyada arena, dreçant los ulls a la lum que,

segni di demarcazione di fine paragrafo, è regolarmente presente nella ripresa intertestuale del passo nel Tirant lo Blanc (“Axí acostuma afalagar ... los grans sostenir no poden!”: Hauf ed. 2005: XVII, $\left.\mathrm{II}_{5}\right)$.

237. cenyhint-se: conservo la lezione di $V$ (con se scritto in interlinea), d'accordo con i precedenti editori (Miquel i Planas: ıo7; Carbonell: I74; Martínez: Io7; Martos 200Ia: ı62; Escartí: I2O), e diversamente da Martos (20I6: 7I) che adduce, sulla scorta di $O$ (seyint), cenyhint. 
ençesa en la torre de Hero, lo seu cor ençenia, tornà altra vegada lançar lo cos en la mar fonda; dient, ab veu per amor esforçada:

"Lo foch que veig ençés alt en la torre

crema dins mi la por de la mar fonda:

ho pendré port en la ylla de Çestos,

ho beuré prest de la mort lo trist càlzer.

$\mathrm{Y}$ ab vostres mans donant-me sepoltura,

vós, per qui muyr, tanquar-m'eu dins la tomba,

lavant lo cos, de làgremes ab l'aygua.

No us espanteu besar ma boca freda".

O escura seguedat d'aquells qui desordenadement amen! E ab quin ànimo, ab quina sotliçitut e diligènçia treballen ensemps l'ànima e la vida perdre! O animosa por de aquells qui reçelant temen los perills de viciós morir e viure, e, ab invençible e discret ànimo, per lo regne del cel la vida abandonen!

Començà la mar un poch detenir la sua fúria per donar loch al ànimo de Leànder e, ja sens temor, l'esforçat jove per l'aygua los braços movia. Gloriós dins si, ab esforç de·namorada esperança, havia vençut l'adverssa fortuna, hi ab recort dels passats delits los esdevenidors contemplant en breu esperava; y en la sua penssa paraules triades treballava conpondre, per rahonar ha Hero los grans perills, los quals, ab esforç de amor, per anar a ella vençent sobrats havia.

(30v) Enujada l'adverssa iniqua fortuna del esforçat ànimo de Leànder, restituhí a la mar furiosa ab multiplicades ones la primera fúria. L'esforç del enamorat mariner, anant al desigat port, no-s canssava; hi ab ales de amor estrema, alçà lo cos sobre les aygües, endreçant la vista a la lum que en la 270 alta torre relluhia, la qual li semblà menor del que acostumava. Hi, reclamant lo nom de Hero, ja prop de la terra, se aparellava pendre posta en la desigada rriba, quant les aygües en gran tempestat aumentaven, fent semblant, ab delliberada fúria, en la destrucció del esforçat jove ab yra terrible totes atenien.

$275 \quad$ No podia a tan gran fúria ja resistir lo miserable Leànder, y les hones altes, venint-li al encontre, de la rriba de Cestos l'apartaven, y.l defenien que ab la vista a la lum de la torre no atteyia; e ja sens orde los braços per l'aygua començava moure, hi era cas de misèria inefable lo treball que per squivar la mort sostenia. E, si un poch espay lo cap de les ones alçava reclamant lo nom de Hero, escupia l'aygua salada, la qual, ab terrible porfídia, volia entrar en lo cos de Leànder; però l'amor de Hero axí tot lo occupava, que a

276-77. y.l defenien que ab la vista: interpungo d'accordo con i precedenti editori (Miquel i Planas: ro8; Carbonell: I75; Martínez: rog; Escartí: I2I) e diversamente da Martos: y.ldefenien, que ab la vista (2оога: 164; 2016: 74).

277. atteyia: si legga attenyia. 
les amargues aygües la entrada defenia. La fortuna vàlida aumentava; les forçes del combatut jove defallien; la fredor de l'aygua la sua persona comprenia; y, per reclamar lo nom de aquella per qui la sua vida se anava perdre, quant més prop de la mort e de la riba se acostava, donà loch les aygües entrassen en los retrets d'on Hero se partia; hi, ab la agonia de la mort que ja.l asaltava, dreçà los ulls a la torre de Hero, per qui moria, hi, abandonat a la fúria de la mar tempestuosa, ensemps ab la ànima tals paraules se partiren:

"Cuyta, cos mort, que l'amor que.t fa perdre

te guiarà fins al peu de la torre:

seguint del foch la miserabl-ensenya,

ffes-te present a la plorosa Hero".

(3Ir) La darrera síl-laba del nom de Hero en aquest món fon terme del seu parlar, amar e viure.

O cosa de gran maravella inefable! Que, semblant a vira de fort ballesta empesa, vench lo seu cos pesat de la salada aygua en la rriba de Çestos, al peu de la torre empès de l'amor que, viu, lo guiava; la qual, per ésser estrema, encara mort lo feÿa córrer, seguint la força que vivint lo empenyia, semblant a laugera galera que, levats los rems, encara ab la fusa pren segura posta. Hi en la boca morta aquell gest guardava, ab lo qual lo nom de Hero se pronunçia.

\section{Pujà Hero en la torre per veure si la mar assossegava}

Al temps que $n$ les amargues aygües l'enamorat miserable per amor de Hero la vida perdia, la enamorada donzella aparellava l'estrado e les teles netes per exugar a Leànder, que de la salada aygua fret e banyat venia. $\mathrm{E}$, pujant en l'alta torre, un poch la lum descobria per endreçar de la sua via lo desigat viatge; e ab diverssos contrasts en sotlícita penssa combatuda, mirant les aygües, desigava nadant passar a la ylla de Abidos, ho en lo camí encontrar a Leànder. E si la mar un poch espay les ones detenia, estimava la entrestida Hero que Leànder, ab pocha amor, lo camí no gosava empendre; $\mathrm{e}$ si les ones la rriba molt fort batien, axí com si la sua veu pogués a les orelles de Leànder atényer, plorant deÿa:

"Si.ls altres hòmens los folls perills recelen per guardar sola una vida, quant més tu, Leànder, los deus més reçelar, qu·ensemps ab la tua tens la mia acomanada, hi est cert la tua sens la mia no pots perdre. No emprengues, donchs, ànima e vida mia, tan perillosa empresa, ni ab tal tempestat lo teu cos, meu, a la furiosa mar acomanes; recort-te lo nadar és

285. donà: correggo, su $O$, la lezione don di $V$, d'accordo con tutti gli editori, a parte Martos: don (2оога: I64; 20I6: 75).

288-89. ab la ànima tals paraules: come i precedenti editori, e diversamente da Martos (200га: І64; 2016: 75; seguito da Escartí: I2I) che integra de la sua boca da $O$ : ab la ànima, de la sua boca tals paraules.

307. via: vida $V$, correggo su $O$, come già i precedenti editori. 
perill que·ls navegants més reçelen, e sinó aprés de naufraig no·l esperimenten, a la hora que en altra manera la vida restaurar no poden, $\mathrm{e}$ molt tart, vius, nadant a la (3I $v$ ) rriba atenyen. Espera lo temps que ab diverssitat lo torn de la sua roda, girant, volta; e penssa quant seria foll aquell qui en joliol, per fogir a la calor, estigués als raigs de Apol-lo, y en giner, per escalfar, çerquàs la freda ombra. Aquesta mar, que ara tan fort crida, pochs dies ha semblant a oli estava segura; e no passarà molt tornarà en la seguretat primera. O gran saviesa! O animós reçel, al temps de la adverssa fortuna estalviar la vida per a la prosperitat esdevenidora! Axí canten les serenes en lo temps de la mar tempestuosa, esperant la tranquilitat quieta. $\mathrm{O}$, quant fóra millor, Leànder, quant aprenguist de nadar, ab l'artefiçi de Dèdalus portasses per l'ayre lo desigat viatge, e lavors sols lo vent, e no la mar, a nostres desigs contrastaria! O gran fortuna mia, que, de quatre elements, los tres, ab totes ses forçes, en la destrucçió nostra ab gran sotliçitut atenen! La terra escassa les nostres çiutats no termena; l'aygua abundant lo nostre freu occupa; l'ayre esforçat al teu nadar, ensemps ab la moguda mar, contrasta; sol lo foch, dins nosaltres y en alta torre, nostres voluntats ajusta. Però yo $\cdot \mathrm{m}$ recort que.l fill de Dèdalus, indiscretament volant, deixà en la mar les plomes e la vida, ab tot que tantes coses, com a tu e a mi, no li contrastassen. Donchs, sola discreçió, que molt tart en los qui amen se troba, té poder dels perills fer-te delliure, trobe’s ara en tu, animós Leànder; $\mathrm{y}$ consent ab la tua amor estrema un poch se acompanye, perquè nostres delits e vida en breu no.s perden”.

\section{Rahonà Hero a la dida la sua gran tristíçia}

Ab tals contrasts, e los ulls corrent aygua, devallà de la alta torre la entrestida Hero; e ans que l'antigua dida la interroguàs per què plorava, a tals paraules, de contínues làgremes acompanyades, féu prinçipi:

"Hoÿt he dir, prudent dida mia, que moltes vegades la mísera penssa pronusticant adevina los dans que la adverssa fortuna procura, ab tristor que.l nostre cor miserable turmenta, ignorant de tal dolor (32r.) la causa. E per ço tinch reçel algun gran infortuni la mia vida asalte: car del retret de la mia ànima sospirs, sens delliber meu, espiren, e los meus ulls, no sé per què, fonts de amargues làgremes brollen. E, ab dolor que lo meu cor travessant esquinça, mirant contemple la roba del qui ab tan gran desig espere. La mia lengua, per estrema tristíçia, no pot clarament pronunçiar lo nom de

328-29. canten les serenes en lo temps ... esperant la tranquilitat quieta: hanno segnalato la continuità tematica tra il passo e l'esparsa corelliana La mort per amor Torró (I996: IO7) e Martínez (2000: 203).

338-39. discreçió ... té poder... delliure, trobe’s ara en tu: intendo trobes di V come trobe's (così già Martos 200Ia: I67; 20I6: 80), simmetrico rispetto al precedente en los qui amen se troba, che assicura una sintassi più scorrevole con discreçió come soggetto. I restanti editori leggono, invece, trobes (Miquel i Planas: ıII; Carbonell: I77; Escartí: ı23; e Martínez: II2). Quest'ultimo opportunamente suggerisce d'intendere té come $i$ té. Quanto alla lezione di $O$ - trobas tu ara en tu animos Leander he consent -, con l'inserimento di tu (e trobas e consent entrambi rivolti, in coordinazione invocativo-esortativa, a Leànder), non è da escludere che sia scaturita da trobes non inteso come "trobe's". 
Leànder".

No pogué més avant parlar la trista donzella, quant respòs la prudent esforçada dida:

"Per fallença de seny, entre-ls més sabents se declara afermar les coses esdevenidores, que sol al gran Júpiter són descubertes. Hi flaquea de ànimo s'estima, ans que la causa de la dolor sia manifesta, avançant sos mals, començar primer a doldre's; ab tot que alguns filòsofs han volgut declarar, quant tristor nos asalta per cosa no sabuda, s’esdevé que, per ésser luny la causa de nostra dolor, no presenta en nosaltres conexença del que.ns dolem, mas una lenta tristíçia, senblant a.quell qui dels enemichs se reçela, que fuig qualsevol que al encontre li vingua, encara que no conegua qui és aquell de qui s'aparta. Però açò és més sompni de vanes fantasies que no veritat declarada, perquè és çerta cosa algú no s’entresteix si primer no té en hoy la causa per què sent tristíçia; ni algú no pot tenir hoy, si primer no coneix.

E axí s'esdevé ara en tu, estimada senyora e filla, que la remor de les braves ones que tota la nit la nostra rriba ab gran fúria baten, a les quals tens gran oy, han entristida la tua enamorada penssa sotlíçita de la venguda de Leànder, a qui mèritament tant ames. Deuries penssar és axí prudent que no empendrà tant perillós viatge, ho, si·l emprén, ab esforç de enamorat ànimo ja acostumat de les ones, passant la mar sobre la qual tantes vegades ha navegat segur viatge, pendrà port en lo teu desigat estrado, e ab aquestes teles les tues mans l'exugaran; e per lo treball, que per tu en aquest més que en los altres viatges ha sofert, ab poch afany lo pregarem qu.entre nosaltres, més del acostu( $32 v)$ mat, descansse".

\section{Aparegué l’ànima de Leànder a Hero}

“O prudent esforçada dida, -respòs la trista donzella- tan gran assento 380 de tristor ha pres dins mi lo reçel de la vida de Leànder, que les discretes paraules dels teus conforts en la mia penssa no troben repòs de posada çerta. Com la mar assossegua, lo meu cor se mor, recelant que Leànder en la falda de algun-altra reposa. E no sé qual de dos mals per major avorreria: ho que, mort per mi en les aygües, fret, banyat estigués en la mia falda e, yo ab ell 385 morta en sos braços, dins un sepulcre nos tanquasses; ho que, vivint de mi apartat, de altra estigués en l'estrado. Quant la mar, movent les braves ones, la sua gran fúria descobre, la mia entristida penssa figura que.l meu Leànder, per mi en les amargues aygües, ja no per mi, mas per la vida, treballa. E axí no són majors les ones que al meu Leànder, si per mi

36o. declarar: sta per "declarar que".

376. ab poch afany lo pregarem: conservo la lezione di $V$, congrua ed esplicita ("Leandro sarà così stremato, che non stenteremo a convincerlo di riposarsi qui più a lungo del solito", ne è il senso), d'accordo con i precedenti editori: Miquel i Planas: II3; Carbonell: ı78;

Martínez: II3; Escartí: I24. Viceversa Martos (200I: I68; 20I6: 83, vid. anche 34, n. го) legge ab poch afany no pregarem, seguendo la lezione di $O$, il cui no (invece di $l o$ ) è una svista.

388. aygües: om. in $V$; integro da $O$, come già i precedenti editori. 
navegua, conbaten, de les que la mia trista dolorada ànima ara turmenten; la qual, en tèrbola aygua de dolor estrema per ell navegant, egualment perilla".

Un gran crit fon la fi de aquestes paraules, semblant a la miserable Hero al encontre dels seus ulls una ombra de la figura de Leànder passava; a la qual, ab veu per dolor e temor alterada e per làgremes e sanglots mal pronunciada, cridant, ab les mans abraçar volia:

"No passes avant, laugera ombra, que yo no·m espante. Si est Leànder, atura ab mi fins que de Leànder lo cos arribe, hi, esperant, pren lo meu per çerta posada; descança un poch en la casa hon, per amor, ab gran delit reposar acostumes. E no pensses, ànima mia de Leànder, larch espay yo·t detingua: comporta que al teu cos, meu, yo done sepoltura, hi aprés, ensemps ab la mia, devallaràs als regnes de Plutó, perquè un carçre, una pena, unes cadenes, aprés la mort liguen aquelles dos ànimes, les quals una amor havia liguat en vida; e axí, los cossos morts, abraçats, estaran en un sepulcre, e nosaltres, en dolor vivint, juntes en una pena".

\section{(33r) Aribà lo cos de Leànder mort a la terra}

¿Hon és Homero, hon és Virgili, qui en metres? ¿Hon és Demòstenes, hon és Tuli, qui en prosa? ¿Hon són los tràgichs grechs e latins poetes, que tanta dolor escriure puguen? ¿Hon són tots los qui tristíçia, dolor e misèria sostenen? Ligen hi entenguen, y ensemps lurs mals obliden, e ploren ab Hero la dolorosa mort de Leànder.

Pujà sens tarda la miserable donzella, ensemps ab la esforçada vella, en la alta torre e, mirant per la lum escura de Diana si Leànder poguera hoyr ho veure, baixà los plorants ulls, que fonts amargues destil-laven, a la rriba hon les ones batien; e ab les mans de la vista apartant les làgremes, conegué lo cors del seu Leànder que.l acostumat gest no portava, ans, la cara girada a la ensenya de la torre, les espatles en la arena, les ones, sens propi moviment del cos, a la rriba lo portaven. Seguí al dolorós mirar un crit de veu espantable:

"O, Leànder!, respon a la tua Hero, la qual, encara viva, mirant te crida!".

No tardara sobre lo cos mort la ja quasi morta donzella, saltant de l'alta torre, acabar de matar-se, sinó que volia, encara vivint, la boca freda besar de Leànder. Rompé los seus cabells, les vestidures ensemps ab lo cuyro dels pits e de la cara, la trista sobre totes les altres adolorada, e, devallant de la torre, per aquella porta secreta que Leànder entrar solia, ixqué al cos mort, banyat hi fret, de aquell qui, ab inefable delit, viu esperava. Hi, estesa sobre lo cos, besant la boca freda, mesclava les sues làgremes calentes ab l'aygua de la mar amargua. E volent pronunçiar, no podia ni sabia tristes paraules a tanta dolor conformes; hi ab les mans tremolant los ulls de Leànder obria,

391. egualment: ab ell egualment legge Martos (200га: I69; 20I6: 85) integrando da $O$ ( $a b$ el); mantengo la lezione di $V$ d'accordo con i precedenti editori (Miquel i Planas: II4; Carbonell: I79; Martínez: II4; Escartí: I24), dal momento che l'assenza di ab ell, non necessario al senso, e in qualche modo implicito in esso, può non essere un'omissione. 
los quals primer ab la boca hi aprés ab los ulls besant axí de abundants làgremes omplia, que semblava Leànder, encara mort, plorant la dolor de la sua Hero viva, planyent deplorava.

No feÿa menor plant la miserable dida, la qual, ensemps per la filla e per Leànder lamentant, la sua dèbil persona ab cruels mans rompia, e de algun remey a (33v) Hero, ja quasi morta, parlar no gosava; perquè és aument de dolor, si en Hero aumentar podia, al que en estrem se dol, fer-li recort la sua dolor remeyar pugua.

\section{Lo plant e mort dolorosa de Hero sobre lo cos de Leànder}

Estava la mar segura, que paria sol contra la vida de Leànder havia pres tanta fúria; lo cel clar, la nit quieta, los ayres, los elements e Diana, los planetes e les esteles, ab una seguretat atenta, al adolorit plant de Hero planyent atenien; los peixos e los oçells, per l'aygua nadant e volant a la rriba, venien a les obsèquies de Leànder, e ab lurs veus ensemps ab Hero dolent, la mort de lur oste planyien. Mas sobre totes plorant sanch, que de aygua les làgremes ja tenia despeses, lamentava, estesa sobre lo cos, aquella que, sola, perdia aquell qui per ella en les aygües havia perdut la vida. E ab paraules que les pedrenyeres, los diamants, l'açer bastarien a rompre, en semblant estil planyent deplorava:

"O, per mi sobre tots miserable Leànder, e per mi en les aygües mort, qui per mi sol en la terra vivies! ¿Quin plant sobre.l teu cos puch yo, encara viva, mirant a tu mort per mi, dignament plànyer? Yo viuré, perquè lo teu naufraig, un poch espay vivint, ab gran dolor lamentant deplore. Que si yo tantost la vida abandone, ¿qui bastarà la tua, mia, iniqua sort mèritament plorant dolre? Donchs viuré yo, perquè la tua mort per mi causada dolgua; e prest per tu morré, e per tu no seré plorada, ab tot que per tu muyra: hi és molta rahó, puix tu primer per mi has perdut la vida.

O lo meu e no de altri, Leànder! Per mi ab los peixos converssaves, als quals ja, nadant, vençies. Per mi avorries la natural terra, y en les salades

430. besant axí de: d'accordo con i precedenti editori (Miquel i Planas: ıi6; Carbonell: I80; Martínez: ıг6; Escartí: I25). Mentre Martos adduce besant, deplorava; axí de (20ога: I7I; 20I6: 88), forse per una svista indotta dal planyent deplorava che appare poco dopo, in chiusura del periodo, dal momento che deplorava (dopo besant) non è presente nei due mss.

432. viva: da notare la variante viu addotta da $O$ (plorant de dolor de la sua Ero viu). A conservare la lezione di $V$ è anche il Tirant nella ben nota ripresa del passo corelliano nel lamento di Carmesina: "que semblava Tirant, encara mort, plorant la dolor de la sua Carmesina viva, planyent deplorava” (Hauf ed. 2005: CCCCLXXIII, I498-99; vid. anche n. 4).

450-51. ¿Quin plant ... plànyer?: come tutti gli editori, tranne Martos (2016: 90): Quin ... plànyer!

453-54. bastarà ... sort mèritament plorant dolre?: bastara la tua mia iniqua sort meritant plorar dolre V; emendo meritant in mèritament, come pure, sulla scorta di $O$ (bastaria la tua mort plorant dolre) plorar in plorant, d'accordo con i precedenti editori (Miquel i Planas: II7; Carbonell: ı8т; Martínez: II7; Escartí: ı26). Viceversa Martos legge: bastarà la tua mia iniqua sort meritant plorar dolre (200Ia: I7I; 20I6: 90). 
aygües prenies deport en delitós viatge. Per mi del teu cos havies fet galera, portant a la rriba de Cestos la mia sobre totes estimada mercaderia; e passant fortuna vàlida, has lançat lo càrrech de la tua ànima, la qual lo teu cos sostenir no podia, per lo pes que, de la mia amor carregada, portava. E axí, lauger, sens càrrech, has pogut surgir ( 34 r.) en la rriba de Cestos, hi estés, fret, banyat hi mort, tens les espatles en aquell loch hon tenies los peus quant, viu, me abraçaves.

O entrestits, piadosos peixos, que ensemps ab mi planyeu la mort del amich vostre Leànder! ¿Per què no li ajudàveu fins al desigat port? Però encara molt vos regraçie manssuetut tan benigne, que lo seu cos entregue haveu aconpanyat fins a la rriba; d'on clarament se mostra viu lo acompanyàveu, si la adverssa fortuna a la sua vida e a la mia tan fort no contrastara.

O miserables pare e mare de Leànder, als quals més temps que a mi la mort del fill serà dolorosa, perquè tant com yo no sabreu la sua mort doldre! E tu, pare meu Austerus, no ab lo gendre que volies, veuràs en un dia les noces e sepoltura de ta filla. E tu, Leànder, perdona si més largues les tues obssèquies no çelebre, que a la mia boca fall la veu hi als meus ulls aygua hi sanch ab què més largament la tua mort deplorant lamente. E si axí morint espire, no poré calfar ni untar lo teu cos ab los engüents que y aparelle: donchs, serà millor que, morint per tu e sobre tu, ab la mia sanch lavant hi $480 \quad$ escalfant lo teu cos ja fret, enbalssemant unte; e ab aquelles teles que per exugar a tu viu aparellades tenia, la mia dida, la qual a tu no menys que a mi amava, abduys abraçats, semblants a un cos, amortallant nos embene, hi en un sepulcre tan estret nos tanque, que.ls nostres ossos mesclats a la fi en una pols se converteixquen; hi, en letres gregues, sobre la nostra tomba, senblant epitafi escolpit escriva:

"Amor cruel, qui.ls has units en vida, y ab gran dolor lo viure.ls has fet perdre, aprés la mort los tanqua $\cdot n^{68}$ lo sepulcre”.

486-88. has units ... has fet ... tanqua.n: conservo la lezione di $V$ (non confrontabile con $O$ che omette il testo dalla 1. 486 alla 1. 493), come già i precedenti editori (Miquel i Planas: ıI8; Carbonell: I82; Martínez: II8), non essendovi controindicazioni sul piano del senso: una invocazione-esortazione a Amore (tanqua $\cdot n)$, non a caso "cruel", fatta in punto di morte, perché, "a compenso" di quanto tolto in vita (has fet perdre), chiuda e sigilli in eterno il simbolo dell'unione dei corpi (oltre che delle anime). Viceversa Martos (20ога: I73; 20I6: 93; seguito da Escartí: 127) emenda la seconda persona (has ... has) in ha units ... ha fet, in funzione del tanca $n$ successivo e della lezione addotta dal Tirant lo Blanc, dove, quasi alla fine del romanzo, il prelievo intertestuale dell'epitaffio corelliano chiude la descrizione del monumento funebre dei due protagonisti. Così, infatti, reca il testo del romanzo: "Amor cruel, qui.ls ha units en vida / y ab greu dolor lo viure-ls ha fet perdre, / aprés la mort los tanque.n lo sepulcre ": Hauf ed. 2005: CCCCLXXXV, I536). E così Martos motiva l' emendamento: "el Tirant serveix per a corregir dues lliçons de l'epitafi ... Modifique la persona verbal dels dos pretèrits indefinits, que no són la segona, com indica $U$ [il Cançoner de Maians] sinó la tercera, com recull correctament el Tirant ... . D’aquesta manera, no cal llegir el verb final com un imperatiu amb el pronom feble en posició proclítica ... D’una altra manera, llegiríem no un to sentenciós, sinó exhortatiu, gens usual en aquests textos funebres corellans" (20I6: 42). Ebbene, la tradizione indiretta - il Tirant lo Blanch - non 
Encara dient aquestes paraules, de greus plors acompanyades, tirà de la bayna la copagorja que la correja de Leànder mort sostenia, e, més lo pom sobre lo cor de Leànder e sobre lo seu la punta, lançant lo cos ab esforç de amor cruel pesada sobre.l de Leànder, espirà la miserable Hero, entre·ls braços frets de aquell mort per qui moria.

\section{Apparato}

I La Istòria de Leànder y Hero] Istoria de Leander hi de Hero feta per mestra Corela $\boldsymbol{O}$ - 2 mediterrana $\boldsymbol{O}$; terzo en] om. $\boldsymbol{O}$; que] om. $\boldsymbol{O}$ - 3 anomenaven $\boldsymbol{O}$ - 5 vedave $\boldsymbol{O}$; sien una scritto in interlinea su en una (depennato) $\boldsymbol{O}$ - 6 Çestos con s finale depennata $\boldsymbol{V}$; he (depennato) de alt $\boldsymbol{O}$ - 7 gràcia e bellea] gran en belesa $\boldsymbol{O}$ - 9 donzella] dona $\boldsymbol{O}$ - Io poseyen $\boldsymbol{O}$ -

II e] e com $\boldsymbol{O}$ - I2 selebren $\boldsymbol{O}$ - I3 Cesto $\boldsymbol{O}$ - I7 al hu hi al altre ] a hu he altre $\boldsymbol{O}$ - I8 ulls] penetrants (scritto in interlinea) uls $\boldsymbol{O}-2 \mathrm{O}$ al hu y al altre] la hu al altra $\boldsymbol{O}-22 \mathrm{Ab}$ ] he ab $\boldsymbol{O}$; descreçió] destruccio $\boldsymbol{O}$ - 25 no li-s encobre] no li es en cobert (cobert: scritto su un precedente cobre) $\boldsymbol{O}$; descobre] corretto in descobri $\boldsymbol{O}$ - 26 Latíbula] la qual avia nom Latibula $\boldsymbol{O}$ - 27 altros $\boldsymbol{O}$ - 30 e gravitat de la tua edat] e gravitat (in interlinea) de la tua edat (edat in interlinea scritto su gravitat depennato $\boldsymbol{O}$ - $3^{\mathrm{I}}$ a terme] en terme $\boldsymbol{O}$; endressen $\boldsymbol{O}$ - 35 ja posible $\boldsymbol{O}$; sinó que] sino $O$; enseps $\boldsymbol{O}$ - 37 a qui ella in interlinea $s u$ aquella depennato $\boldsymbol{O}$ - $3^{8}$ altres sues] suas $\boldsymbol{O}$ -

42 mia penssa] pensa $\boldsymbol{O}$; enlegir] legir $\boldsymbol{O}$ con en in interlinea su una lettera depennata - 43 viçiosos tractes] virtuos tracte $\boldsymbol{O}$; semblans $\boldsymbol{O}$ - 44 guesten $\boldsymbol{V}$ - 45 deu] pot $\boldsymbol{O}$ - 46 elegir] legir $\boldsymbol{O}$ - 47 menys] manco $\boldsymbol{O}-5^{\mathrm{O}-} 5^{\mathrm{I}}$ no solament seguito da no salament depennato $\boldsymbol{O}_{-} 5^{\mathrm{I}}$ a] ha inserito in interlinea $\boldsymbol{O}-53$ senyora la possehiries] senyor posehiries $\boldsymbol{O}$ -

54 Partís Leànder de la çiutat de Cestos] Com Leander se parti de Cesto $\boldsymbol{O}$ - 57 porien $\boldsymbol{O}$ - 6o6I desdenyat del matrimoni, ab esperança perduda] tenia (aggiunto da mano correttrice nel margine esterno) desdeyat (depennato) del matrimoni la (la scritto in interlinea su ab depennato) speransa perduda $\boldsymbol{O}$ - 62 un poch] ab un poch $\boldsymbol{O}$ - 63 passant] hi pen (n raschiata) ssant $\boldsymbol{O}$ - 64 Cesto $\boldsymbol{O}$ - 65 que los altros $\boldsymbol{O}$; no u] no $\boldsymbol{O}$ - 66 sesquinsa $\boldsymbol{O}-67$ no·m asalte] nom accepta $\boldsymbol{O}$ - 69 a vós] e vos $\boldsymbol{O}$; porta $\boldsymbol{O}$ - 7 I vostros $\boldsymbol{O}$; d'onesta] de nostra $\boldsymbol{O}$ -

74 parlaven $\boldsymbol{O}$; a] ab con b depennata $\boldsymbol{O}=75$ dopo seny: he raschiato $\boldsymbol{O}$ - 77 anomenave $\boldsymbol{O}$ - 78 entre los $\boldsymbol{O}$ - 79 per a gendre] per apendra $\boldsymbol{O}$; desert in interlinea su descret depennato $\boldsymbol{O}$; morals] mortals

può essere decisiva sotto il profilo della ricostruzione; per di più i contesti, e la contestualizzazione, dell'epitaffio, tra la faula e il romanzo, sono diversi. Nel romanzo l'epitaffio è parte integrante di una “sepultura triomfal”, celebrativa della gloria cavalleresca e nel contempo commemorativa dell'amore, già data e descritta come monumento funebre della (e per la) memoria collettiva (sulla cui segnicità vid. Martínez r998). Nella Istòria i tre versi che lo compongono sgorgano dalla (e nella) dimensione ancora intimistica di un pianto-compianto d'amore. Né può essere condizionante il pronome (los) antecedente l'imperativo, dal momento che tale uso non è ignoto al catalano antico (vid. Moll I952: 363 ). D'altronde los fa parte di un asse fonico allitterante (la ... los ... lo), all'interno del quale los, subito dopo la cesura e richiamato da lo, guadagna dalla stessa posizione un' accentuazione della sua (forte) carica semantica. 
$\boldsymbol{O}$ - 8I permet que $\boldsymbol{O}$ - 84 entra los $\boldsymbol{O}$; a Leànder in interlinea $\boldsymbol{O}$ - 85 per al] al $\boldsymbol{O}$ - 86 no in interlinea $\boldsymbol{O}$; indisposiçions in interlinea su scusacions depennato $\boldsymbol{O}$; sua in interlinea $\boldsymbol{O}$ - 88 sua persona $\boldsymbol{O}$ -

9I-95 que una entrestida continença...ençenia] que una trista continensa cobria la calor (calor corretto in color) de la cara sua he magrida tota la persona ab continua tristicia sens manifesta causa descobrien que algun pensament en los retrets de la sua pensa aflagint la turmentaven ab continuus sospis sospirant seyelaven lo ffoch de la amor de Leander las suas entramanas cremant encenia $\boldsymbol{O}$-97 prima di pes] hi astrema amor depennato $\boldsymbol{O}$; perdre] a perdra $\boldsymbol{O}$ - 98 que lo $\boldsymbol{O}$ - Ior tristura] tristicia $\boldsymbol{O}$ - IO2 puiant in interlinea $\boldsymbol{O}$; Hero] Ero scritto su mar $\boldsymbol{O}$ - IO3-IO4 sseus ulls] ulls $\boldsymbol{O}$-IO4 en] ab $\boldsymbol{O}$ -

IO8 sua tristor] dolor sua $\boldsymbol{O}$ - III criada] donzela $\boldsymbol{O}$ - II2 cor] $\cos \boldsymbol{O}$ - II2-II3 de la tua bella delicada persona] de la tua (tua in interlinea) bellesa (bella corretto in belle $e$ con sa in interlinea) e (in interlinea) delicade persona $\boldsymbol{O}$ - II 4 quont $\boldsymbol{O}$ - II5 aporta $\boldsymbol{O}$; l'accepte] la accepta $\boldsymbol{O}$ - II6 fas continent vols] fas tal plant continuament vols $\boldsymbol{O}$ - II8 abundona $\boldsymbol{O}$ - I2O ab tu] en tu $\boldsymbol{O}$; portem] portem con scritto sopra, in interlinea, pus fermament $\boldsymbol{O}$; carro] carrech $\boldsymbol{O}$ scritto in interlinea in corrispondenz a di caros depennato $\boldsymbol{O}$ - I2I tens preceduto da tens depennato $\boldsymbol{O}$; manifesta] con e supra lineam in corrispondenza di una lettera forse una e corretta perché resa poco leggibile dal tratto stesso che ne ha riempito l'occhiello $\boldsymbol{O}$; secrets que $\boldsymbol{V}$ - I22 a] ab $\boldsymbol{O}$; de in interlinea $\boldsymbol{V}$ - I23 ton] tot $\boldsymbol{O}$; atengues $\boldsymbol{O}$ - I25 endressa $\boldsymbol{O}$ -

I29 he presa] e apressa $\boldsymbol{O}$ - I30 ha tengut] a tenguda $\boldsymbol{O}$ - I3 aportas $\boldsymbol{O}$ - I33 ha] $\mathrm{om}$. $\boldsymbol{O}$ - I34 respondren $\boldsymbol{O}$ con $n$ finale aggiunta sembra da altra mano $\boldsymbol{O}$; conporte $\boldsymbol{O}$; vida se va a] vidas va (va in interlinea in corrispondenza di a depennata) $\boldsymbol{O}$ - I36 a] ab $\boldsymbol{O}$ - I38 andressats $\boldsymbol{O}$; lagrimejant $\boldsymbol{O}$ - I38-I39 tardà Latíbula tornar] torna Latibula tornant $\boldsymbol{O}$ - I40 si lo $\boldsymbol{O}$ - I42 a ton] he a ton $\boldsymbol{O}$ - I43 aportas $\boldsymbol{O}$ - I 45 trista] plorosa $\boldsymbol{O}$ - I 46 vol a] vol $\boldsymbol{O}$; no u] no $\boldsymbol{O}$; E] om. $\boldsymbol{O}$ - I47 per] in interlinea $\boldsymbol{O}$ - I 48 quant] com $\boldsymbol{O}$ - I49 primo ni] no $\boldsymbol{O}$ - I5o per què a tots avorreixch] e avoresch $\boldsymbol{O}$-I5 I a Exosus] axosus $\boldsymbol{O}$; a Leànder] Leander $\boldsymbol{O}$ -

I53 descriure] descra con iu supra lineam $\boldsymbol{O}$ - I55 les altres] totas las altres $\boldsymbol{O}$ - I56 enbanat $\boldsymbol{O}$; he honesta $\boldsymbol{O}$ - I58 cometria $\boldsymbol{O}$; miserable scritto in interlinea su honesta depennato $\boldsymbol{O}$ - I59 l'amor] lo amor $\boldsymbol{O}$ - I6o la (aggiunto in interlinea da altra mano) amor $\boldsymbol{O}$-I6 sa depennato $\boldsymbol{V}$ - i65 quont $\boldsymbol{O}$ - I66 quolsevol $\boldsymbol{O}$; contrectar con r finale scritta su s $\boldsymbol{O}$ - i67 E] om. $\boldsymbol{O}$; morta] poco leggibile in $\boldsymbol{O}$ a causa del distaccamento dello strato superiore della carta - I68 digna] om. $\boldsymbol{V}$ - I69 in efable $\boldsymbol{O}$ con un segno abbreviativo su efable; que los $\boldsymbol{O}$ - I7O a] en $\boldsymbol{O}$; Cesto $\boldsymbol{O}$ - I72 Leànder ans] ans Leander $\boldsymbol{O}$; a perdre $\boldsymbol{O}$ - I73 fon lo conçert que] concerta la discreta vella ab Leandre que $\boldsymbol{O}$ - I74 plaers] ples $\boldsymbol{O}$; Leànder nadant passàs] passas nadant $\boldsymbol{O}$ - I75 dues] ditas $\boldsymbol{O}$; tardar $\boldsymbol{O}$ - I76 Cesto $\boldsymbol{O}$ -

I77 de la çiutat de Cestos] de Cesto $\boldsymbol{O}$; ab conçert e gran alegria] ab gran alegria $\boldsymbol{O}$ - I70 Ab conçert e gran alegria ] ab alegria $\boldsymbol{O}$; e in interlinea $\boldsymbol{O}$ - I79 Cesto $\boldsymbol{O}$ - I8o-I8I en alegre cativeri cativa] ab alegra cativeri catiu (catiu depennato) $\boldsymbol{O}$-I82 per a la nit] en la nit $\boldsymbol{O}$-I84 esforç] forçat $\boldsymbol{O}$; fonda] tant fonda $\boldsymbol{O}$ - I86 que los $\boldsymbol{O}$; estenien] stenen $\boldsymbol{O}$ - I87 sorguint $\boldsymbol{O}$ - I88 cors e la ànima] cos he anima $\boldsymbol{O}$ I89 acaminava] continuave $\boldsymbol{O}$; paria ja] paria $\boldsymbol{O}$ - I9o senda] sende preceduto da de depennato $\boldsymbol{O}$ - I9I altros $\boldsymbol{O}$; navilis in interlinea su marines depennato $\boldsymbol{O}$ - I92 en la proha] e la proa $\boldsymbol{O}$ - I93 Cesto $\boldsymbol{O}$; aportave $\boldsymbol{O}$; tornant] tornat $\boldsymbol{O}$ - I96 aporta $\boldsymbol{O}$ - I97 lo in interlinea $\boldsymbol{O}$-I97-I98 la pròspera fortuna] lo prosperar fortuna $\boldsymbol{O}$ - 200 Cesto $\boldsymbol{O}$; voliia $\boldsymbol{O}$ - 2OI acustumave con ve depennato $\boldsymbol{O}$; quont $\boldsymbol{O}$; al qui] algui corretto con q in interlinea $\boldsymbol{O}$ - 202-2O3 aquell a qui prospera] aquel qui amor prospera $\boldsymbol{O}-2 \mathrm{O} 3$ arma $\boldsymbol{O}$; infortuni] furtuni $\boldsymbol{O}$; que $\operatorname{los} \boldsymbol{O}$ - 204 neguna $\boldsymbol{O}$ - 205 sostenir no poden] aggiunto da mano correttrice sui segni di riempimento tra un paragrafo e l'altro $\boldsymbol{O}$ - 
206 secondo de la] $\mathrm{om}$. $\boldsymbol{O}$ - 207 havia] avia con a finale in interlinea $\boldsymbol{O}$ - 208-209 los vents a moure les aygües més del que acostumat havien] los vents moures les aygues mes que acustumat havian $\boldsymbol{O}$ - 209 aparellava's] aperellaves scritto nel margine esterno, preceduto da apere corretto supra lineam in ab peraules poi depennato, e seguito al rigo successivo da laves depennato; lo asforsat $\boldsymbol{O}$ - 2I2 que tantes vegades com s'enterboleix l'aygua] com tantas vegades com laygue se enterbola $\boldsymbol{O}$ - 2I3 En] en preceduto da h depennata $\boldsymbol{O}$; conech] preceduto da convint depennato $\boldsymbol{O}$ - 2I 4 quont $\boldsymbol{O}$; iniqua sort ] mia sort $\boldsymbol{O}$; clamava] clamaria corretto con va in interlinea su ria $\boldsymbol{O}$ - 2I5 podia] poria $\boldsymbol{O}$; Ara] he ja $\boldsymbol{O}$ - 2I6 blasfeme, perquè] blasfemave que $\boldsymbol{O}$ - 2I7 comenar $\boldsymbol{O}$; e, per] per $\boldsymbol{O}$; tots $\boldsymbol{O}$ - 2I8 vivens $\boldsymbol{O}$ - 2I82I9 E com és poch espay lo que a mon voler contrasta] he com mes puch sperar lo que a mon voler contrasta $\boldsymbol{O}$ - 220 deman $\boldsymbol{O}$; ni veles] no veles $\boldsymbol{O}$ - 22I mire] mirar $\boldsymbol{O}$; per que lo $\boldsymbol{O}$ - 222 trobar $\boldsymbol{O}$ - 223 per a mi] per mi $\boldsymbol{O}$; mire, és la estela a la qual] miren en la stella en la qual $\boldsymbol{O}-224$ e lo] lo $\boldsymbol{O}-226$ per a] per $\boldsymbol{O}$; als altres ] per altres $\boldsymbol{O}$ - 226-227 amargua!, un poch la tua fúria... cobrada la fúria] amaga un poch la tua furia $\boldsymbol{O}$ (omissione per omeoteleuto) - 227 fes] e (in interlinea) fes $\boldsymbol{O}$ - 228 prima di justa] jos depennato $\boldsymbol{O}$ - 229 spera $\boldsymbol{O}$; quont $\boldsymbol{O}$; soplich $\boldsymbol{O}$ - 23o que lo $\boldsymbol{O}$ - 23I taraçana del estrado] tarrasana $\boldsymbol{O}$ - 233 dura $\boldsymbol{O}$ -

235 en la mar Leànder] Leander en la mar $\boldsymbol{O}$ - 236 enseps $\boldsymbol{O}$ - 237 vestia's] vestis $\boldsymbol{O}$; cenyhint-se] con se in interlinea $\boldsymbol{V}$, seyint $\boldsymbol{O}$; una correja] un corega $\boldsymbol{O}$ - $239 \mathrm{E}]$ om. $\boldsymbol{O}$; acomanà] acomanave $\boldsymbol{O}$ - 242 de peus ] den peus $\boldsymbol{O}$ - 243 cor] $\cos \boldsymbol{V}$ - 244 forsada $\boldsymbol{O}$ - 245 alt] om. $\boldsymbol{O}$ - 247 ylla] riba $\boldsymbol{O}$; Cesto $\boldsymbol{O}$ - 248 beuré] beura $\boldsymbol{O}$ - 25 ab l'aygua ] ab aygua $\boldsymbol{O}$ - $253 \mathrm{Eab}$ ] ab $\boldsymbol{O}$ - 254 ensemps scritto in interlinea su sens depennato $\boldsymbol{O}$ - 256 e, ab] he preceduto da ab depennato $\boldsymbol{O}$ - 257 habundonen $\boldsymbol{O}-258$ la mar un poch] un poch la mar $\boldsymbol{O}$ - 26o esforç] foch $\boldsymbol{O}$ - 26I-262 en breu esperava] en $g$ ( $\mathrm{g}$ depennata) breu speransa $\boldsymbol{O}$ - 262 triades] preceduto da tals depennato $\boldsymbol{V}$; conpondre] comprendre $\boldsymbol{O}$ - 262-263 per rahonar] per areonar $\boldsymbol{O}$ - 263 rahonar preceduto da h depennata $\mathbf{V}$; anar] amar $\boldsymbol{O}$ -

- 266 iniqua] he ininiqua $\boldsymbol{O}$; forsat $\boldsymbol{O}$ - $268 \mathrm{ab}$ ] om. $\boldsymbol{V}$ - $27 \mathrm{O}$ alta] altra con $\mathrm{r}$ con un segno di rasura $\boldsymbol{O}$; dopo qual] aguessem depennato $\boldsymbol{O}$ - 27 I posta] posada $\boldsymbol{O}$ - 272 quont $\boldsymbol{O}$ - 273 la destrucció] destruccio $\boldsymbol{O}$ - 275 ja resistir] resistir $\boldsymbol{O}-{ }_{2} 76$ Cesto $\boldsymbol{O}$ - 278 començava moure] comensaven a moure $\boldsymbol{O}$ - 279 reclamant] clarament $\boldsymbol{O}$ - 280 laygua laygua $\boldsymbol{V}$ - 28O-28I escupia...Hero] om. $\boldsymbol{O}$ (per omeoteleuto) - 28I acupave $\boldsymbol{O}$ - 28I-282 a les amargues aygües la entrada defenia] las amargues aygues ja en terra defenia $\boldsymbol{O}$ - 282 augmentaven $\boldsymbol{O}$ - 283 defallien] defanian $\boldsymbol{O}$; persona persona $\boldsymbol{O}$ - 285 quont $\boldsymbol{O}$; don $\boldsymbol{V}$ - 286 agonia] angonia scritto in interlinea su angoxa depennato $\boldsymbol{O}$ - 287 dresse $\boldsymbol{O}$; vulls $\boldsymbol{V}$ - 288 abondonant $\boldsymbol{O}$; enseps $\boldsymbol{O}$ - 288-289 tals paraules] de la sua boca talls paraules $\boldsymbol{O}$ - 289 partian $\boldsymbol{O}$ - 292 del foch] lo ffoch $\boldsymbol{O}$ - 293 plorosa] miserable $\boldsymbol{O}$ - 296 O] e $\boldsymbol{O}$; gran maravella] maravela $\boldsymbol{O}$; fort scritto in interlinea su gran depennato $\boldsymbol{V}$ - 297 empesa] om. $\boldsymbol{O}$; vench] vens $\boldsymbol{O}$; seu cos] cos $\boldsymbol{O}$; Cesto $\boldsymbol{O}$ - 298 ompes $\boldsymbol{O}$ - 3 oo a laugera galera] a la galera $\boldsymbol{O}$; fua $\boldsymbol{O}$ - 3 OI guardava] mostrave $\boldsymbol{O}$ - 302 pronunciave $\boldsymbol{O}$ -

303 per veure] per auera $\boldsymbol{O}$ - $3 \mathrm{O} 4$ l'enamorat miserable] lo miserable $\boldsymbol{O}$ - $306 \mathrm{E}$ l om. $\boldsymbol{O}$ - $3 \mathrm{O}$ - descobria] descobri $\boldsymbol{O}$; via ] vida $\boldsymbol{V}$ - 3 O8 la sollicita $\boldsymbol{O}$ - 3 O9 desigava nadant] desigant nedant $\boldsymbol{O}$ - 3IO a Leànder] Leander $\boldsymbol{O}$; E] om. $\boldsymbol{O}$ - 3II entrestida Hero] intristida de Ero $\boldsymbol{O}$; lo camí no gosava empendre] no gastave (gastave in precedenza scritto ganave) lo cami en pendre $\boldsymbol{O}$ - 3 I2 la rriba ] a la riba $\boldsymbol{O}$; la sua veu] lavores $\boldsymbol{O}$ - 3 I 4 si als $\boldsymbol{O}$; gordar $\boldsymbol{O}$ - 3 I5 quant] com $\boldsymbol{O}$; més] om. $\boldsymbol{O}$; enseps $\boldsymbol{O}$ - 3I 6 acomanada] en comanda $\boldsymbol{O}$; est] es $\boldsymbol{O}$; no pots] nos pot $\boldsymbol{O}$ - $3 \mathrm{I} 7$ ab] en $\boldsymbol{O}$ - 3 I8 acomanes] acomanar $\boldsymbol{O}$; recort-te] recort seguito da a depennata te $\boldsymbol{O}$ - $3^{\mathrm{I} 9}$ que los $\boldsymbol{O}$ - 319-320 no-l esperimenten] lo asperimenten $\boldsymbol{O}$ - $32 \mathrm{O}$ en altra] en ta (ta depennato) altra $\boldsymbol{O}$ - 32 I nadant a la rriba] a la riba $\boldsymbol{O}-3^{2 \mathrm{I}-322}$ que ab diverssitat ] que adversitat $\boldsymbol{O}$ - 322 quont $\boldsymbol{O}$ - 323 als raigs de Apol.lo] al rag (rag depennato, con xt in interlinea pure depennato) raxt del sol $\boldsymbol{O}$ - 324 çerquàs] om. $\boldsymbol{O}$; freda] fresca $\boldsymbol{O}$; tan fort] fort $\boldsymbol{O}$ - 325 crida] triada $\boldsymbol{O}$; ha semblant a oli] asenblat ala (ala depennato) a oli $\boldsymbol{O}-3^{2} 5^{-326}$ passarà molt tornarà en] pensara 
tornara gayra ha $\boldsymbol{O}$ - 328 canten] cansten (con depennazione in scribendo di s) $\boldsymbol{O}$; mar tempestuosa] tempestuosa mar $\boldsymbol{O}$ - 329 quont $\boldsymbol{O}$; Leànder] animos Leander $\boldsymbol{O}$; quont $\boldsymbol{O}$ - 33I desigs] desigits $\boldsymbol{O}$; contrastaria] contrastara $\boldsymbol{O}$; $\operatorname{cotra} \boldsymbol{O}$ - 333 atenen] venen $\boldsymbol{O}$; no termena] lo termene $\boldsymbol{O}$ - 334 lo nostre freu] freu $\boldsymbol{O}$ - 335 lo foch] fon $\boldsymbol{O}$; nosaltres] nosaltres preceduto da nostres abbreviato senza titulus e depennato in scribendo $\boldsymbol{O}$; alta] lalta $\boldsymbol{O}$ - 336 que lo $\boldsymbol{O}$ - 337 deixà] deya $\boldsymbol{O}$; mar] marr con la prima r depennata $\boldsymbol{O}$; e la vida] a la vida $\boldsymbol{O}$ - 338 contrastassen] contrasta $\boldsymbol{O}$; discreçió] destruccio $\boldsymbol{O}$ - 339 amen se] amensan con $\mathrm{n}$ finale depennata $\boldsymbol{O}$; trobes ara en tu] trobas tu ara en tu $\boldsymbol{O}$ - $34 \mathrm{O}$ ab] en $\boldsymbol{O}$; se acompanye] aconpaya $\boldsymbol{O}$ - $34 \mathrm{I}$ en breu] he breu $\boldsymbol{O}$ -

342 gran tristíçia] tristicia $\boldsymbol{O}$ - 343 corents $\boldsymbol{O}$; devallà] devale $\boldsymbol{O}$ - $344^{-345}$ a tals] ab tals $\boldsymbol{O}$ - 346 mísera] miserable $\boldsymbol{O}$ - 347 endivina $\boldsymbol{O}$ - 348 que lo $\boldsymbol{O}$ - 349 infortuni la mia vida asalte: car] infortuni assalte car $\boldsymbol{O}$ - 350-352 espiren, e ... esquinça] cor (con $\mathrm{r}$ forse corretta in e) squiu sens travessa $\boldsymbol{O}$ - $35^{2}$ contempla $\boldsymbol{O}$; la roba del qui] de qui $\boldsymbol{O}$; spera $\boldsymbol{O}$ - 355 pogué] pogues con s finale depennata $\boldsymbol{O}$; quont $\boldsymbol{O}$; repos con s inserita in interlinea $\boldsymbol{O}$ - $355^{-35} 6$ prudent esforçada dida] sforsada vella $\boldsymbol{O}$ - 357 entre.ls] en te (te depennato) tre los $\boldsymbol{O}$; sabents] sabuts $\boldsymbol{O}$ - 36 o alguns filòsofs] alguns per si $\boldsymbol{O}$ - $3^{6 \text { I }}$ quant] quonta $\boldsymbol{O}$; luny] lum $\boldsymbol{O}$ - 362 del que.ns dolem] del que volem $\boldsymbol{O}$ - 363 mas una] $\mathrm{om}$. $\boldsymbol{O}$; senblant a quell qui dels enemichs se reçela] qui dels amichs semblant aquels (aquels con s depennata) se resela $\boldsymbol{O}$ - 364 qualsevol] aquol sevol $\boldsymbol{O}$; vingue $\boldsymbol{O}$; conegue $\boldsymbol{O}$ - 365 s'aparta] se aparta preceduto da aparta depennato $\boldsymbol{O}$; Però] per $\boldsymbol{O}$ - 366 perquè és çerta] per esser certa $\boldsymbol{O}$; s'entresteix si primer] se entristex qui primer $\boldsymbol{O}-367-368$ tenir hoy, si primer no coneix. E axí] tenir en oy no conex que axi $\boldsymbol{O}-369$ la nostra rriba ab gran fúria] ab gran furia la nostre ribe $\boldsymbol{O}$ - $369-37 \mathrm{O}$ tens gran oy] tant gran oy $\boldsymbol{O}$ - $37 \mathrm{O}$ entristit $\boldsymbol{O}$ - 37 és axí] que es axi $\boldsymbol{O}$ - 37 I-372 no empendrà tant perillós viatge] tant perilos viatge no enpendra $\boldsymbol{O}$ - 372 esforç] fort $\boldsymbol{O}$ - 373 passant la mar] pensant pessant la mar $\boldsymbol{O}$ - 374 pendrà] pendrie $\boldsymbol{O}$ - 374-375 e ab aquestes teles les tues mans l'exugaran] ab aquestas telas le axugaran $\boldsymbol{O}$ - 376 lo pregarem qu·entre] no pregarem que ab $\boldsymbol{O}$ - 377 descans $\boldsymbol{O}$ -

379 prudent esforçada] prudent he forsade $\boldsymbol{O}$ - 380 ha pres] a (depennata) e pres $\boldsymbol{O}$ - 38I en] om. $\boldsymbol{O}$ - $3^{82}$ assosegue $\boldsymbol{O}$; mor] mon $\boldsymbol{O}$ - $3^{83}$ quals $\boldsymbol{O}$; avorreria] avaricia $\boldsymbol{O}$ - $3^{84}$ bayant $\boldsymbol{O}-3^{84} 4^{8} 55$ ab ell morta en sos braços] ab el abrassats $\boldsymbol{O}$ - 385 nos] no con s aggiunta in interlinea $\boldsymbol{O}$; vivint de mi] vivint ab (ab scritto in interlinea su de depennato) mi $\boldsymbol{O}$ - 386 quont $\boldsymbol{O}$ - $3^{80}$ que lo $\boldsymbol{O}$ - $3^{88}$ aygües] om. $\boldsymbol{V}$ - 389 que al] que lo $\boldsymbol{O}$ - 390 navegan con $\mathrm{n}$ finale depennata $\boldsymbol{O}$; de les que la mia trista] que ma trista $\boldsymbol{O}$ - 39I egualment] ab el agualment $\boldsymbol{O}$ - 393 aquestes] aques scritto con s maiuscola poi corretto in aquestas soprascrivendo st in legamento e di seguito as $\boldsymbol{O}$ - 394 ala encontra $\boldsymbol{O}$ - 395 ab veu per dolor e temor] per veu ab dolor he tamor $\boldsymbol{O}$ - 398 lo meu] lo meu $\cos \boldsymbol{O}$ - 4 OO acustumaves $\boldsymbol{O}$; E no pensses] not penses $\boldsymbol{O}$ - 4 OI detinguals $\boldsymbol{O}$; comporta que al teu cos, meu, yo done] porta que al teu cos he meu jot dave $\boldsymbol{O}$ - 402 ab la mia, devallaràs] davalaras $\boldsymbol{O}$ - 403 duas $\boldsymbol{O}$ - 404 ligades $\boldsymbol{O}$; en un] ab hun $\boldsymbol{O}-405$ juctes $\boldsymbol{O}$ -

406 a la terra] en terra $\boldsymbol{O}$-407 en metres] ab metres $\boldsymbol{O}$-408-4IO los tràgichs...ploren] tragichs grechs latins poetas que tanta dolor de tristura pugan en on son tots los qui dolor tristicia descriura puguen hi enseps lus malls obbliden hi ploren $\boldsymbol{O}$ - 4I2 enseps $\boldsymbol{O}$ - 4I3 torre e, mirant per la lum escura de Diana] torre de Diana $\boldsymbol{O}$ - $4 \mathrm{I} 4$ plorants] plorosos $\boldsymbol{O}$ - 4I4-4I5 hon les ones] ont les aygues $\boldsymbol{O}$ - 4I5 apartant] apartave $\boldsymbol{O}$ - $4 \mathrm{I} 6$ aportave $\boldsymbol{O}$ - 417 dopo espatles] g depennata $\boldsymbol{V}$; en la arena] a la arena $\boldsymbol{O}$ $4 \mathrm{I} 8$ al dolorós] ab doloros $\boldsymbol{V}$ - 420 mirant te crida] te criade $\boldsymbol{O}$ - 42 I lo cos] lo teu cos $\boldsymbol{O}$ - 422 acabar de matar-se] acabar se de matar $\boldsymbol{O}$; besar] encara bessar $\boldsymbol{O}$ - 423 vestitudures con tu depennato $\boldsymbol{O}$; enseps $\boldsymbol{O}$ - ${ }_{42} 4$ trista] trista he $\boldsymbol{O}$ - 425 mort] mosrt (s depennata) $\boldsymbol{O}$ - ${ }_{42} 6$ aquel seguito da o con un segno forse di correzione $\boldsymbol{O}$; delit] desig $\boldsymbol{O}$-427-428 calentes ab l'aygua de la mar amargua] ab aygue $\boldsymbol{O}$ - 428 E volent] volent $\boldsymbol{O}$; ja pronunciar $\boldsymbol{O}$; podia preceduto da pd depennato $\boldsymbol{V}$ - 428 -429 a tanta dolor 
conformes] he tanta dolor confortas $\boldsymbol{O}$ - 430 hi aprés] apres $\boldsymbol{O}$; ulls] seus uls $\boldsymbol{O}$ - 43I omplia] onpli $\boldsymbol{O}$; semsblave (con seconda s depennata) $\boldsymbol{O}$ - 43-432 plorant la dolor de la sua Hero viva] plorant de dolor de la sua Ero viu $\boldsymbol{O}$ - 433 dida] vella $\boldsymbol{O}$; enseps $\boldsymbol{O}$ - 434-435 e de algun remey a] de algun remey he (he depennato) ha (ha corregge un precedente he) $\boldsymbol{O}$ - 435 parlar no gosava] no parlalave (col primo la depennato) $\boldsymbol{O}$ - 436-437 fer-li recort la sua dolor remeyar pugua] fer recort de la sua dolor remeyar pugua la (la depennato) $\boldsymbol{O}$ -

$43^{8}$ sobre lo cos de Leànder] sobre de (de in interlinea) Leander lo cors $\boldsymbol{O}$ - 440-44I los elements e Diana, los planetes] e los vents diana e las planetas $\boldsymbol{O}$ - 44I atenta] atenia $\boldsymbol{O}$ - 443 e ab] ab $\boldsymbol{O}$ - 444 planyien] playent $\boldsymbol{O}$; la sanch $\boldsymbol{O}$ - 445 dopo lamentava] Ero scritto in interlinea $\boldsymbol{O}$; estesa] he astesa (con la prima a depennata) $\boldsymbol{O}$; lo cos] los (con s depennata) cors de (cors de in interlinea) $\boldsymbol{O}$ - 447 rompe $\boldsymbol{V}$ - 447-448 en semblant] ab semblant $\boldsymbol{O}$ - 449 tots] tots los vivens $\boldsymbol{O}$; e per mi] o per mi $\boldsymbol{O}$ - 45 O mi in interlinea $\boldsymbol{O}$; o quin $\boldsymbol{O}$; sobre lo $\boldsymbol{O}$ - 45 $\mathrm{I}^{\mathrm{I}} 45^{2}$ dignament...deplore] plany vivint ab greu dolor lamentant deplore $\boldsymbol{O}$ - 453 abandone in interlinea su bundone depennato $\boldsymbol{O}$ - $453-454$ bastarà...dolre] bastara la tua mia iniqua sort meritant plorar dolre $\boldsymbol{V}$; bastaria la tua mort plorant dolre $\boldsymbol{O}$ - 454 yo scritto in interlinea su ja depennato $\boldsymbol{O}$; mi] om. $\boldsymbol{O}$; causadas $\boldsymbol{O}$; dolgue $\boldsymbol{O}$ - 454-455 e prest] prest $\boldsymbol{O}$ - 455 seré] astare $\boldsymbol{O}$ - 456 tu primer] tu $\boldsymbol{O}$; perduda $\boldsymbol{O}$ - 457 altre $\boldsymbol{O}$ - $45^{8}$ salades] cansades $\boldsymbol{O}$ - 459 feta $\boldsymbol{O}$ - 460 Cesto $\boldsymbol{O}$ - 46r lo qual $\boldsymbol{O}$ - 462 que] om. $\boldsymbol{O}$; aportava $\boldsymbol{O}$ - 462-463 axí, lauger, sens càrrech, has pogut] axi Leander sens carech es pogut $\boldsymbol{O}$ - 463 rribal ila $\boldsymbol{O}$; Cesto $\boldsymbol{O}$; estés] stas $\boldsymbol{O}$ - 464 tenies] scritto in interlinea su reyes depennato $\boldsymbol{O}$ - 465 quont $\boldsymbol{O}$ - 468 encara molt vos regraçie] en vos regraciaria $\boldsymbol{O}$ - 468-470 entregue haveu aconpanyat ... lo acompanyàveu] entegra acompayaveu $\boldsymbol{O}$ (omissione per omeoteleuto) - $47^{2}$ miserables ... als quals] miserable pare he mare de Leander al qual $\boldsymbol{O}$ - 472-473 la mort] om. $\boldsymbol{O}$ - 473 perquè] quasi del tutto illeggibile per danneggiamento della carta, e forse preceduto da q depennata $\boldsymbol{V}$; com] quont $\boldsymbol{O}$ - 474 Asterus $\boldsymbol{O}$; que] preceduto da que lo depennato $\boldsymbol{O}$ - 475 perdona] om. $\boldsymbol{O}$ - 476 salebra $\boldsymbol{O}$; que a la] que la $\boldsymbol{O}$; boca fall] leggibile solo parzialmente $\boldsymbol{V}$ - 477 lamenta $\boldsymbol{O}$ - $47^{8}$ spira $\boldsymbol{O}$; que y aparelle] que ja aparellats havia $\boldsymbol{O}$ - 479 la in interlinea $\boldsymbol{O}$ - 480 enbalssemant] he en bl (bl depennato) balsamat $\boldsymbol{O}$; unta $\boldsymbol{O}$; e] om. $\boldsymbol{O}$ - 48 i tenia] preceduto da avia depennato $\boldsymbol{O}$; lo qual $\boldsymbol{O}$; a tu preceduto da no depennato $\boldsymbol{O}$ - 482 amave] preceduto da amave depennato $\boldsymbol{O}$; a un cos, amortallant] a un cos amortallat $\boldsymbol{V}$; un cors mortallant $\boldsymbol{O}$; enbena $\boldsymbol{O}$ - 483 tanqua $\boldsymbol{O}$; que los $\boldsymbol{O}$; nostros $\boldsymbol{O}$ - 485 scriura $\boldsymbol{O}$ - 486-493 Amor cruel...moria] om. $\boldsymbol{O}$.

\section{Ringraziamenti}

L'autore ringrazia i due revisori anonimi per l'accurata lettura dell'articolo e per i proficui suggerimenti. Un segno particolare di riconoscenza va alla Dr. Serena Ammirati, Università Roma Tre, per la competenza paleografica generosamente messa a disposizione. 


\section{Opere citate}

Ahuir i López, Artur (ed.). r997. Les proses profanes de Joan Rö̈ç de Corella (València: L’Oronella)

Almiñana Vallés, Josep (ed.). r984-I985. Obres de Joan Roiç de Corella, 2 vols València: Del Cénia al Segura)

Annicchiarico, Annamaria (ed.). 1983-1987. La Fiammetta catalana: edizione critica, con introduzione, note e glossario, 2 vols (L'Aquila: Japadre)

Annicchiarico, Annamaria. 1996. Varianti corelliane e 'plagi' del 'Tirant': Achille e Polissena (Fasano di Brindisi: Schena Editore)

Annicchiarico Annamaria. I998. 'Voglia di pathos e un'altra connexió: Fiammetta e Corella nel Tirant lo Blanch,' Caplletra: Revista Internacional de Filologia, 24: 25-44

Annicchiarico, Annamaria. 1999. 'Presenza e presenza-assenza di Madonna Fiammetta e di Corella nel Tirant lo Blanc', in Estudis sobre Joan Roís de Corella, ed. by Vicent Martines (Alcoi: Editorial Marfil), pp. 55-69

Annicchiarico Annamaria. 2004. 'L’edizione critica delle Faules mitologiche di Joan Roís de Corella: bilanci, sondaggi, proposte', La Parola del Testo: Semestrale di Filologia e Letteratura Europea dalle Origini al Renascimento (=Studi in onore di Giuseppe E. Sansone, vol. 2), 8.2: 44366

Annicchiarico, Annamaria. 20o6. 'Edizione e traduzione: Joan Roís de Corella', in La traduzione è una forma: trasmissione e sopravvivenza dei testi romanzi medievali, ed. by Giuseppina Brunetti e Gabriele Giannini, Quaderni di Filologia Romanza, 19: 57-75

Annicchiarico, Annamaria. 20I4. 'Tra Ero e Fiammetta: la retorica dell'amore ne La Istòria de Leànder y Hero de Joan Roís de Corella', in Joan Roís de Corella i el seu món (València: Institució Alfons el Magnànim), pp. 29I-322

Annicchiarico, Annamaria (ed.). 20I6. 'Joan Roís de Corella, Lamentació de Mirra, de Narciso, de Píramus i Tisbe: edizione critica', Magnificat Cultura i Literatura Medievals, 3: I-35<https://ojs. uv.es/index.php/MCLM/article/view/8I32>

Badia, Lola. I988. "En les baixes antenes de vulgar poesia": Corella, els mites i l'amor', in her De Bernat Metge a Joan Roís de Corella: estudis sobre la cultura literària de la tardor medieval catalana (Barcelona: Quaderns Crema), pp. I45-80 <

Badia, Lola. 1993. 'Per la presència d'Ovidi a l'Edat Mitjana catalana, amb notes sobre les traduccions de les Heroides i de les Metamorfosis al vulgar', in her Tradició i modernitat als segles XIV i XV: estudis de cultura literària i lectures d'Ausiàs March (València: IIFV; Barcelona: PAM), pp. 39-7 [ [first published in Studia in honorem prof. M. de Riquer, Barcelona: Quaderns Crema, I986, I: 79-Io9] <http://tinyurl.com/h756nqf>

Badia, Lola. 20I5: 'La ficció sentimental', in Història de la literatura catalana, ed. by Àlex Broch (Barcelona: Enciclopèdia Catalana; Barcino; Ajuntament de Barcelona), III: Literatura medieval (III): segle XV, ed. by Lola Badia, I9O-209

Barbieri, Luca. 20II. 'Les Héroüdes dans l'Ovide moralisé: Léandre-Héro. Pâris-Hélène. JasonMédée', in Les Translations d'Ovide au Moyen Âge: Actes de la journée d'études internationale à la Bibliothèque royale de Belgique 20o8,' ed. by An Faems, Virginie Minet Mahy and Colette Van 
Coolput-Storms (Louvain-la-Neuve: Publications de l’Institut d'Études Médiévales), pp. 235-68

Barchiesi, Alessandro (ed.). 2OII. Ovidio Metamorfosi, II, Libri III-IV, 3rd edn (Milano: Fondazione Lorenzo Valla; Mondadori)

Bettarini, Rosanna (ed.). 2005. Francesco Petrarca Canzoniere. Rerum Vulgarium Fragmenta, 2 vols (Torino: Einaudi)

Boer, Cornelis de (ed.). I9I5-I938. Ovide moralisé, poème du commencement du quatorzième siècle, publié d'après tous les manuscrits connus, 5 vols (Amsterdam: J. Müller)

Bohigas, Pere; Soberanas, Amadeu J.; Espinàs, Noemí (ed.). 2005. Ausiàs March Poesies (Barcelona: Barcino)

Bologna Corrado. 20o6. 'Compassio Virginis', La Parola del Testo: Semestrale di Filologia e Letteratura Europea dalle Origini al Renascimento, I0.2: 219-89

Bolzoni, Lina. 2002. La rete delle immagini: predicazione in volgare dalle origini a Bernardino da Siena (Torino: Einaudi)

Brancaforte, Benito (ed.). I990. Las 'Metamorfosis' y las 'Heroidas' de Ovidio en la 'General Estoria' de Alfonso el Sabio (Madison: The Hispanic Seminary of Medieval Studies)

Branciforti, Francesco (ed.). 1959. Piramus et Tisbé: introduzione, testo critico, traduzione e note (Firenze: Olschki)

Bulbena, Antoni (ed.). I896-97. 'Istoria de Leander hi de Hero feta per mestra Corella', in Libre intitulat "Jardinet de Orats"(Barcelona: Biblioteca de la Revista de Catalunya), pp.29-46

Bulbena, Antoni (ed.). I9O7. 'Historia de Leànder hi Ero', in Crestomatía de la llenga catalana (Biblioteca Clàssica Catalana), pp.25 ${ }^{\mathrm{I}} 55$

Carbonell, Jordi (ed.). I973. Joan Roís de Corella Obres completes, I: Obra profana (València: Clàssics Albatros)

Chiner Gimeno Jaume J. r99. 'Batalla a ultrança per Joanot Martorell', A Sol Post: Estudis de Llengua i Literatura, 3: 83-127

Chiner Gimeno, Jaume J. 20I3. ‘ [Joan Roís de Corella] L’autor’, Biblioteca Virtual Joan Lluís Vives <http://www.cervantesvirtual.com/portales/rois de corella/autor/>

Chiner Gimeno Jaume J. 20I4. 'Joan Roís de Corella, la seua vida i el seu entorn: noves dades per a la història de la cultura en la València del segle xv', Magnificat Cultura i Literatura Medievals, I: III-377 <https://doi.org/IO.7203/MCLM.I.3934>

Cingolani Stefano M. 1997. ‘D’Aquil-les a Jesús: reflexions sobre la cronologia de les obres de Joan Roís de Corella', in Anuari de l'Agrupació Borrianenca de Cultura (= De literatura i cultura a la València medieval, ed. by Tomàs Martínez), 8: 67-85 <http://repositori.uji.es/xmlui/ handle/IO234/4678>

Cingolani, Stefano M. 1998. Joan Roús de Corella: la importància de dir-se honest (València: Edicions Tres i Quatre)

Corella, Joan Roís de. I998. [Ludolphus de Saxonia, Meditationes Vitae Christi] Lo quart del Cartoxà aromançat per Johan Roiç de Corella, València, Lope de la Roca 1495 (edició facsímil de l'exemplar conservat en la Biblioteca Serrano Morales), introd. by Jaume J. Chiner (València: Ajuntament de València) 
Delcorno, Carlo (ed.). 1994. Elegia di Madonna Fiammetta, in Giovanni Boccaccio Tutte le opere, ed. by Vittore Branca (Milano: Mondadori), v.II

Delcorno Branca, Daniela. 2OI2. 'Diffusione della materia arturiana in Italia: per un riesame delle "tradizioni sommerse", in Culture, livelli di cultura e ambienti nel Medioevo occidentale, ed. by Francesco Benozzo, Giuseppina Brunetti et al. (Roma: Aracne), pp. $3^{2 \mathrm{I}-40}$

Di Girolamo Costanzo; Siviero Donatella. 1999. 'Da Orange a Beniarjó (passando per Firenze): un'interpretazione degli estramps catalani', Revue d'Études Catalanes, 2: 8I-95 <http://www. rialc.unina.it/bollettino/base/empuries.htm>

Escartí, Vicent J. (ed.). 20II. Isabel de Villena Vita Christi (València: Institució Alfons el Magnànim)

Escartí, Vicent J. (ed.). 20I4. Joan Roís de Corella Obra completa (València: Institució Alfons el Magnànim)

Fedeli, Paolo (ed.). 1999. Dalla poesia d'amore alla poesia dell'esilio, in Ovidio Opere (Torino: Einaudi), I

Ferrando Francés Antoni; Escartí Vicent J. 1998. 'Impremta i vida literària a València en el pas del segle XV al XVI, Butlletí de la Societat Castellonenca de Cultura (= Cultura i humanisme en les Iletres hispaniques, s. XV-XVI, ed. by Germà Colon and Lluís Gimeno Betí), 74.I: I6I-78

Fratta, Aniello (ed.). 2005. Jordi de Sant Jordi Poesies, Els Nostres Clàssics B, 26 (Barcelona: Barcino)

Gaggero Massimiliano. 2005. "Sunt duo, nec duo sunt": l'uguaglianza d'amore nella narrativa francese del XII secolo', Critica del Testo, 8.I: 69-ІІ2

Garcia Sempere, Marinela. 1999a. 'Algunes connexions entre l'obra religiosa i l'obra profana de Joan Roís de Corella: l'Oració i la prosa mitològica de La Història de Leànder i Hero', in Estudis sobre Joan Roís de Corella, ed. by Vicent Martines (Alcoi: Editorial Marfil), pp. I69-8I

Garcia Sempere, Marinela. 1999b. 'La Istòria de la Passió, un poema narratiu de Bernat Fenollar i Pere Martines', in Ausiàs March i el món cultural del segle XV, ed. by Rafael Alemany Ferrer (Alacant: IIFV), pp. 3I9-4I

Garcia Sempere, Marinela. 200o. 'La Oració a la Verge Maria de Joan Roís de Corella', in Proceedings of the Ninth Colloquium of the MHRS, ed. by Andrew M. Beresford and Alan Deyermond, PMHRS, 26 (London: Queen Mary and Westfield College), pp. 25-30

Garcia Sempere, Marinela (ed.). 2002. Lo passi en cobles (1493): estudi i edició (Alacant: IIFV; Barcelona: PAM)

Garcia Sempere, Marinela; Martín Pascual Llúcia. 2009. 'El dolor de Maria: la passió de la Mare de Déu en la literatura catalana medieval', in Medievalismo en Extremadura: estudios sobre literatura y cultura hispánicas en la Edad Media (Cáceres: Universidad de Extremadura), pp. 563-74

Garriga, Carles. 1991. 'Caldesa i Carmesina: Roís de Corella plagiat en el Tirant lo Blanc', in Estudis de Llengua i Literatura Catalanes, 23 (=Miscel.lània Jordi Carbonell, vol. 2) (Barcelona: PAM), pp. $17-27$

Gómez Francesc J. 2008. 'Per a una nova lectura amorosa i consolatòria dels "cants de mort" d'Ausiàs March', Llengua \& Literatura, 19 : 49-85 <https://tinyurl.com/yarx8k4m >

Gómez, Francesc; Pujol, Josep (ed.). 20o8. Ausiàs March Per haver d'amorvida: antologia comentada (Barcelona: Barcino) 
Gómez, Francesc J. 20I5: 'Joan Roís de Corella: proses d'inspiració clàssica i cortesa', in Història de la literatura catalana, ed. by Àlex Broch (Barcelona: Enciclopèdia Catalana; Editorial Barcino; Ajuntament de Barcelona), III: Literatura Medieval (III): segle XV, ed. by Lola Badia, pp. 222-42

Guia i Marín, Josep. 1996. De Martorell a Corella: descobrint l'autor del 'Tirant lo Blanc'(Catarroja: Editorial Afers)

Guia i Marín, Josep. 1999. Fraseologia i estil: enigmes literaris a la València del segle XV (València: Tres i Quatre)

Gustà, Marina (ed.). r980. Joan Roís de Corella Tragèdia de Caldesa i altres proses (Barcelona: Edicions 62; "la Caixa")

Hauf, Albert. 1990. D'Eiximenis a Sor Isabel de Villena: aportació a l'estudi de la nostra cultura medieval (València: IIFV; Barcelona: PAM)

Hauf, Albert (ed.). 2005. Joanot Martorell (Martí Joan de Galba) Tirant lo Blanch (València: Tirant lo Blanch)

Hauf, Albert. 20II. 'Tirant lo Blanc', in Panorama crític de la literatura catalana (Barcelona: Vicens Vives), II: Edat Mïana. Segle d'or, ed. by Albert Hauf , pp. 204-64

Izquierdo, Josep. 1994. 'Els planctus Mariae a les literatures catalana i occitana: l'Augats, seyós qui credets Déu lo Payre', in Miscel-lània Joan Fuster: estudis de llengua i literatura catalana, ed. by Antoni Ferrando and Albert Hauf (Barcelona: PAM), vIII: 5-23

Lechat, Didier. 2002. Héro et Léandre dans l'Ovide moralisê, Cahiers de Recherches Médiévales et Humanistes (= Lectures et usages d'Ovide, ed. by Emmanuèle Baumgartner) , 9: 25-37 <https:// doi.org/I0.4000/Crm.54 $>$

Lippi, Emilio (ed.).r996. Giovanni Girolamo Nadal Leandreride (Padova: Editrice Antenore)

López Quiles, Antoni. 2007. Literatura i espiritualitat: aproximació a l’obra de Corella com a resposta davant Déu i l'home (València: Institució Alfons el Magnànim)

López Quiles, Antoni. 20I4. 'La proposta sapiencial de Corella', in Joan Roís de Corella i el seu món (València: Institució Alfons el Magnànim), pp. 389-422

Lozano, Josep; Añon, Magda (ed.). 1998. Joan Roís de Corella Leandre i Hero. Història de Josep (Alzira: Edicions Bromera)

Martines, Vicent. 20I3. 'Els elements plàstics en l'obra de Joan Roís de Corella: pintar amb paraules els amors de Leànder i Hero', in Afers: Fulls de Recerca i Pensament (= Dossier Joan Roís de Corella: noves aportacions, ed. by Antoni Ferrando), 76: 66I-685

Martínez, Tomàs (ed.). r994. Joan Roís de Corella Rims i proses (Barcelona: Edicions 62)

Martínez, Tomàs. 1998. 'Funus triumpho simillimum? Consideracions al voltant de la mort i del dol per Tirant lo Blanc', Butlletí de la Societat Castellonenca de Cultura (= Cultura i humanisme en les lletres hispaniques, s. XV-XVI, ed. by Germà Colon and Lluís Gimeno Betí), 74.I: 23-48

Martínez Tomàs. 200o. 'De poesia i lògica corellana: comentaris a La mort per amor', Estudis Romànics, 22: 197-212

Martínez Tomàs. 200I. 'Joan Roís de Corella interpretat des d’Ausiàs March', Cultura Neolatina, 6r: I59-94

Martínez, Tomàs. 20II: 'Joan Roís de Corella i la literatura a la València de la segona meitat del xv', 
in Panorama crític de la literatura catalana (Barcelona: Vicens Vives), II: Edat Mitjana. Segle d'or, ed. by Albert Hauf, pp. 435-77

Martos, Josep Ll. I999. 'El Cançoner de Maians (BUV MS 728): un cançoner d'autor de Joan Roís de Corella' , in Estudis de Llengua i Literatura Catalanes, 39 (=Homenatge a Arthur Terry, vol. 3) (Barcelona: PAM), pp. 93-II3

Martos, Josep L1. 20oo. 'El epitafio de Hero y Leandro en la obra de Joan Roís de Corella', in Proceedings of the Ninth Colloquium of the MHRS, ed. by Andrew M. Beresford and Alan Deyermond, PMHRS, 26 (London: Queen Mary and Westfield College), pp. 85-94

Martos, Josep Ll. (ed.). 2oora. Les proses mitològiques de Joan Roís de Corella: edició crítica (Alacant: IIFV; Barcelona: PAM) <http://tinyurl.com/zm3qX3r $>$

Martos, Josep L1. 20oIb. Fonts i seqüència cronològica de les proses mitològiques de Joan Roís de Corella (Alacant: Universitat d'Alacant. Departament de Filologia Catalana)

Martos, Josep Ll. 20oic. 'La génesis de un cancionero catalán de autor: Joan Roís de Corella y el Cançoner de Maians', in Canzonieri Iberici, ed. by Patrizia Botta, Carmen Parilla, Ignacio Pérez Pascual (A Coruña: Editorial Toxosoutos; Universidade da Coruña; Padova: Università di Padova), pp. 3I3-328

Martos Josep Ll. 2005a. 'El Còdex de Cambridge, el Cançoner de Maians y el Jardinet d'orats a través de la obra de Roís de Corella', in Los cancioneros españoles: materiales y métodos, ed. by Manuel Moreno \& Dorothy S. Severin, PMHRS, 43 (London: Queen Mary, University of London), pp. II3-I40

Martos, Josep Ll. 2005b. “"Con li suoi vestimenti asciugare il morto viso della salata acqua, e bagnarlo di molte lagrime": la Fiammetta en el Leànder y Hero de Roís de Corella', Caplletra: Revista Internacional de Filologia, 39: 257-275

Martos, Josep Ll. 20I4. 'La poesia de Joan Roís de Corella: textos de rematada', in Joan Roís de Corella i el seu món (València: Institució Alfons el Magnànim), pp. 487-507

Martos, Josep Ll. (ed.). 20I6. 'La istòria de Leànder y Hero de Joan Roís de Corella: transmissió textual, anàlisi ecdòtica i edició crítica', in The Story of Leander and Hero by Joan Roís de Corella: A Multilingual Edition of a Classic from the Crown of Aragon, ed. by Antonio Cortijo Ocaña and Josep Ll. Martos (Amsterdam: John Benjamins), pp. I9-94

Meneghetti, Maria Luisa. 20I5. Storie al muro: temi e personaggi della letteratura profana nell'arte medievale (Torino: Einaudi)

Mezzetti Radaelli Monia. 2007. 'Due cuori e un sepolcro: il motivo della sepoltura degli amanti in alcuni testi francesi e italiani del Medioevo', La Parola del Testo: Semestrale di Filologia e Letteratura Europea dalle Origini al Renascimento, II.I: 7-26.

Migne, Jacques Paul. I844- Patrologiae cursus completus, Series Latina, 22I vols, Paris (vid. Patrologia Latina Database)

Miquel i Planas, Ramon (ed.). r9ı3. Obres de J. Roiç de Corella (Barcelona: Casa Miquel Rius 'Biblioteca Catalana')

Miralles Carles. 1998. 'Corella i el Tirant: qüestions d'intertextualitat', Caplletra: Revista Internacional de Filologia, 24: 67-79 < $\underline{\text { http://www.cervantesvirtual.com/obra/corella-i-el- }}$ $\underline{\text { tirant }>}$

Moll, Francesc de B. 1952. Gramática histórica catalana (Madrid: Editorial Gredos) 
Morros Mestres Bienvenido. 20I3. 'La moralización del Leandro de Boscán: orígenes, difusión e interpretación de una fábula', Studia Aurea: Revista de Literatura Española y Teoría Literaria del Renacimiento y Siglo de Oro, 7: 199-266 <https://doi.org/IO.5565/rev/studiaaurea.74>

Moya del Baño, Francisca.I966. El tema de Hero y Leandro en la literatura española (Murcia: Universidad de Murcia) <http://interclassica.um.es/monografias/el tema de hero_y $\underline{\text { leandro }}>$

Murgia Giulia. 20I5. 'Il tema della tomba degli amanti nella Tavola ritonda a confronto con la tradizione tristaniana francese e castigliana', Critica del Testo, I8.2: 9-50

Paz y Mélia, Antonio (ed.). 1907. Cancionero y obras en prosa de Fernando de la Torre, Gedruckt für die Gesellschaft für Romanische Literatur, I6 (Dresden: Max Niemeyer) <https:/ /archive.org/ details/CancioneroYObrasEnProsaPazYMelia>

Pellisa Prades, Gemma. 20I3. La ficció sentimental catalana de la segona meitat del segle XV (unpublished doctoral thesis, Universitat de Barcelona) $\langle\underline{\text { https: / tinyurl.com/ycpgppvs }}>$

Presotto, Marco (ed.). 1997. Juan de Dueñas La nao de amor. Misa de Amores: edizione critica, studio introduttivo e commento (Viareggio-Lucca: Mauro Baroni)

Pujol Josep. 1988-89. ‘Els versos estramps a la lírica catalana medieval’, Llengua \& Literatura, 3: 4I-87

Pujol Josep. 1995-96. 'El desenllaç tràgic del Tirant lo Blanc, les Troianes de Sèneca i les idees de tragèdia al segle Xv', Boletín de la Real Academia de Buenas Letras de Barcelona, 45: 29-66 $<\underline{\text { https://tinyurl.com/yazr2h8o }}>$

Pujol, Josep. 2002. La memòria literària de Joanot Martorell: models i escriptura en el 'Tirant lo Blanc'(Barcelona: Curial Edicions Catalanes; PAM)

Pujol Josep. 2005. 'Les glosses de Guillem Nicolau a la seva traducció de les Heroides d'Ovidi (I390): una proposta d'identificació', Caplletra: Revista Internacional de Filologia, 39: 199-229

Pujol Josep. 20I3. 'Noves fonts ovidianes, pràctiques escolars i Boccaccio al Leànder i Hero de Joan Roís de Corella', Cultura Neolatina, 73: I53-83

Pujol Josep. 20I4. 'Para las fuentes del Bursario: la traducción catalana de las Heroidas de Guillem Nicolau y su versión castellana anónima', Bulletin of Hispanic Studies, 9I.5: 453-76 < https://doi. org/IO.3828/bhs.20I4.29>

Pujol, Josep. 20I5: 'Tirant lo Blanc', in Història de la literatura catalana, ed. by Àlex Broch (Barcelona: Enciclopèdia Catalana; Editorial Barcino; Ajuntament de Barcelona), III: Literatura Medieval (III): segle XV, ed. by Lola Badia, pp. IO7-6I

Pulega, Andrea.I989. Da Argo alla nave d'amore: contributo alla storia di una metafora (Firenze: La Nuova Italia)

Punzi, Arianna. 2007. “"Entre ses bras", in Parole e temi del romanzo medievale, ed. by Anatole P. Fuksas (Roma: Viella), pp. II-37

Quaglio, Antonio Enzo (ed.). r967. Filocolo, in Giovanni Boccaccio Tutte le opere, ed. by Vittore Branca (Milano: Mondadori), I

Ravasini, Ines (ed.). 2008. Comendador Escrivá Poesie: edizione critica, introduzione e commento (Viareggio-Lucca: Mauro Baroni)

Reed, Joseph D. (ed.). 20I3. Ovidio Metamorfosi (Milano: Fondazione Lorenzo Valla; Mondadori), 


\section{v: Libri X-XII}

Renedo, Xavier. 1995-I996. 'Raó i intuïció en Plaerdemavida', Boletín de la Real Academia de Buenas Letras de Barcelona, 45: 317-360

Rico, Francisco (ed.). 1984. 'Imágenes del Prerrenacimiento español: Joan Roís de Corella y la Tragèdia de Caldesa', in Estudios de literatura española y francesa, siglos XVI y XVII: homenaje a Horst Baader (Frankfurt: Klaus Dieter Vervuert), pp.I5-27

Riquer, Martí de. I949. Nuevas contribuciones a las fuentes del 'Tirant lo Blanch' (Barcelona: Biblioteca Central)

Riquer, Martí de. 1964. Història de la literatura catalana: part antiga, 3 vols (Barcelona: Ariel)

Riquer, Martí de. I99o. Aproximació al 'Tirant lo Blanc'(Barcelona: Quaderns Crema)

Riquer, Martí de; Badia, Lola (ed.). I984. Les poesies de Jordi de Sant Jordi, cavaller valencià del segle XV (València: Tres i Quatre)

Rodríguez Risquete, Francisco J. (ed.). 2OII. Pere Torroella Obra completa, 2 vols, Els Nostres Clàssics $\mathrm{B}, 3^{\mathrm{I}-32}$ (Barcelona: Barcino)

Rychner, Jean (ed.). r966. Les lais de Marie de France (Paris: Champion)

Saquero Suárez-Somonte, Pilar; González Rolán, Tomás (ed.). I984. Juan Rodríguez del Padrón Bursario (Madrid: Universidad Complutense)

Saquero Suárez-Somonte, Pilar; González Rolán, Tomás (ed.). 2oio. Juan Rodríguez del Padrón Bursario (Alcalá de Henares: Centro de Estudios Cervantinos)

Sarmati, Elisabetta. 2009. Naufragi e tempeste d'amore: storia di una metafora nella Spagna dei Secolid'Oro (Roma: Carocci)

Serés, Guillermo. 1996. La transformación de los amantes: imágenes del amor de la Antigüedad al Siglo de Oro (Barcelona: Crítica)

Soler, Abel. 2OI4. Joan Roís de Corella (1435-1497): síntesi biogràfica i aportació documental (València: Acadèmia Valenciana de la Llengua)

Thiry-Stassin, Martine; Tyssens, Madeleine (ed.). 1976. Narcisse: conte ovidien français du XII siècle (Paris: Les Belles Lettres) $<$ http://tinyurl.com/jtjod5m $>$

Tilliette, Jean Yves (ed.). 1998-2002. Baldricus Burgulianus / Baudri de Bourgueil Carmina/ Poèmes, 2 vols (Paris: Les Belles Lettres).

Torró, Jaume. 1987. Lo despropriament de amor de Romeu Llull (Barcelona: Stelle dell'Orsa)

Torró Jaume. I992. 'El ms. I5I de la Biblioteca Universitària de Barcelona (Jardinet de orats): descripció i estudi codicològic', in Boletín Bibliográfico de la Asociación Hispánica de Literatura Medieval, 6.I, pp.I-55

Torró Jaume. 1996. 'El mite de Caldesa: Corella al Jardinet d'orats', Atalaya: Revue Française d'Études Médiévales Hispaniques, 7: IO3-I 6 https://tinyurl.com/y7zpylzy $>$

Tosi, Renzo. 1993. Dizionario delle sentenze latine e greche, gth edn (Milano: Rizzoli)

Walther, Hans. 1982-1986. Proverbia sententiaeque Latinitatis Medii ac Recentioris Aevi. Nova Series: Lateinische Sprichwörter und Sentenzen des Mittelalters und der frühen Neuzeit in alphabetischer Anordnung, ed. by Paul Gerhard Schmidt, 3 vols (Göttingen: Vandenhoeck \& 
Ruprecht)

Wittlin, Curt. 1993. 'Joan Roís de Corella. Introducció a una concordança de les seves obres', in Actes del novè col-loqui de llengua i literatura catalanes: Alacant-Elx 1991, ed. by Rafael Alemany, Antoni Ferrando and Lluís Meseguer (Barcelona: PAM: Alacant: Universitat d'Alacant), I: 327-66

Wittlin Curt. 1995. 'Un text inèdit de Joan Roís de Corella: La visió a la porta de la Senyora Nostra de Gràcia, del I487', A Sol Post: Estudis de Llengua i Literatura, 3: 257-68 <http:/ /www. cervantesvirtual.com/obra/un-text-inedit>

Wittlin, Curt. 1997. 'La Biblis, Mirra i Santa Maria de Joan Roís de Corella: traduccions modulades, amplificades i adaptades', in Anuari de l'Agrupació Borrianenca de Cultura (=De literatura $i$ cultura a la València medieval, ed. by Tomàs Martínez), 8: I75-89 <http://repositori.uji.es/ xmlui/bitstream/handle/10234/4696> 